\title{
25 Research Square \\ Study on the Influence Law of Forming Quality of Clinched Joint for Dissimilar Metal Sheet
}

Qihan Li

Changchun University of technology

Chuanwei Xu ( $\nabla$ chuanwei_xu_sdly@163.com )

Changchun University of Technology https://orcid.org/0000-0001-6773-4533

\section{Song Gao}

Changchun University of technology

\section{Xiaoheng Han}

Changchun University of technology

\section{Fenglei Ma}

Changchun University of technology

\section{Dongwei Gu}

Changchun University of technology

\section{Qingming Zhao}

Changchun Schmidt Automation Technology

\section{Research Article}

Keywords: Clinching, Heterogeneous thin sheet, Numerical simulation, Process parameters, neck-lock ratio

Posted Date: June 9th, 2021

DOI: https://doi.org/10.21203/rs.3.rs-578350/v1

License: (c) (i) This work is licensed under a Creative Commons Attribution 4.0 International License.

Read Full License 


\section{Abstract}

The clinched process of heterogeneous materials is more and more used in automobile, aerospace, and household appliances manufacturing. Traditional spot welding is easy to produce heat influence and damage material itself, which restricts the application and development for the hybrid structure of the vehicle body. This paper is based on the test of clinching. The cross-section morphology of clinched joints is observed. Based on the tensile test data and the requirements of the test die, the finite element model of the steel-aluminum clinched joint forming is established. The model is proved to be effective in the process of clinched forming. Based on the simulation model, the influence of process parameters (forming process parameters, Punch's geometry parameters, and concave die structural parameters) on the forming quality of steel- aluminum clinched joint is analyzed. The evaluation of the joint after forming includes the critical dimension, deformation, and neck-lock ratio. Then, the strength of the steel-aluminum clinched joint was studied by tensile shear test. The law of strength change and the neck-lock ratio is analyzed. The selection strategy of different process parameters is studied. The results show that the forming process of the joint is predicted by numerical simulation, and the quality of the joint is sound. The neck-lock ratio of the joint with the highest tensile and shear strength is less than one and close to 1 , that is, the joint with forming force of $40 \mathrm{kN}$. The tensile strength and shear strength of clinched joint are higher than the design index (shear strength is $1700 \mathrm{~N}$, tensile strength is $700 \mathrm{~N}$ ). The tensile strength was increased by $125 \%$, and the shear strength was $62.35 \%$.

\section{Introduction}

With the rapid development of lightweight technology, high-strength steel and aluminum alloy are widely used in designing and manufacturing the vehicle body with good plastic processing properties. For the sake of realizing the difference in control of the performance of the body structure, the components of high-strength steel and aluminum alloy are often used in combination. Conventional steel aluminum heterogeneous joints are generally welded ${ }^{[1]}$ and typical riveted connections ${ }^{[2]}$. The joint strength produced by spot welding is high. But it can destroy the coating on the metal surface. Producing metal compounds that reduce strength; The dynamic and static strength of joints produced by typical rivets is good. But in the forming process, rivet damage materials, energy consumption, and investment cost are high. For the sake of realizing the connection between steel and aluminum, the clinched process has been developed. However, due to the significant difference in physical and chemical properties of steel and aluminum, how to realize a connection between high-strength steel and aluminum alloy for clinching has become a hot research topic in the field of body manufacturing ${ }^{[3]}$. The development of numerical simulation provides an effective way to obtain the prediction of joint forming. It simplifies the actual forming process of process. The forming prediction is realized by using the finite element software, and the influence of the process parameters on the forming joint is analyzed. The product's development cycle is shortened, and a large amount of die manufacturing cost is saved. Therefore, the numerical simulation method is widely used in the forming of clinching. 
As a kind of cold extrusion forming technology, the clinching has a variety of die structures. At present, the experiment and simulation can realize the non-destructive connection between thin sheets. The test can genuinely reflect the forming effect of the joint. Abe et al. ${ }^{[4]}$ successfully connected the ultra-highstrength and low plasticity steel sheet by adjusting the die parameters and compared the strength of clinched joint and spot welding joint. The results show that mechanical clinching has high fatigue strength. Atia and Jain ${ }^{[5]}$ used dieless clinching process to connect 7075 aluminium alloy sheets with different tempering conditions $(0, \mathrm{~W}, \mathrm{~T} 6)$. The flow behaviour, neck thickness and interlocking characteristics of the material during clinching were analyzed. The mechanical properties and failure forms of the joint were obtained through single shear lap and peel tests. Mucha and Witkowski ${ }^{[6]}$ successfully joined dx51d + Z / 275 galvanized sheet and obtained the maximum strength of the joint through the strength test of single shear lap specimen, $\mathrm{H}$-shaped specimen and T-shaped specimen. With the development of clinching for aluminium alloy sheet, high protrusion and low strength are not suitable for connecting particular structures. Because of the above problems, Chen et al. ${ }^{[7]}$ proposed a clinchingreshaping process suitable for aluminium alloy sheet, which adopted two steps of clinching and flat pressing reshaping, reduced the joint bulge height and successfully improved the connection strength of 5052 aluminium alloy and 6061 aluminium alloy. Chen et al. ${ }^{[8]}$ also, compared to the joint quality of the two methods, the results show that the strength of the two kinds of joint is higher than that of the clinched joint, and the strength of the joint with die shaping is the highest. 6061 aluminium alloy plate was successfully connected by two compressing methods of clinched joints, which was formed by Chen et al. ${ }^{[9]}$, and the tensile and shear strength was improved by Chen et al. ${ }^{[10]}$. Subsequently, Chen et al. ${ }^{[11]}$ studied the reshaping of aluminium alloy clinched joints with different thicknesses, and the strength was improved compared with that before reshaping. This technology can be used for the joints requiring high strength and low protrusion. Clinched joints will be deformed or damaged when they bear an enormous shear force. A new repair process was proposed by Chen et al. ${ }^{[12]}$. The process is suitable for repairing deformed/damaged clinched joints. Furthermore, the repaired joints have higher shear strength ${ }^{[13-14]}$. Compared with other joints, the strength of the repaired joint is higher. The thin sheet connection materials studied above are mainly homogeneous metal, and the clinched die has become mature. At present, the clinching has entered the field of dissimilar material connection, its connection quality is better, and its strength is higher than that of homogeneous material connection. Huang and Yanagimoto ${ }^{[15]}$ proposed a heat-assisted plastic deformation steel aluminium bonding process for metal sheet, which can obtain high-quality joints through high-temperature activated interfacial atomic interdiffusion. The connection process has good connection performance, lightweight, simple operation and extended die life. Lambiase and $\mathrm{Ko}^{[16]}$ studied the feasibility of clinched process between carbon fibre reinforced polymer (CFRP) and aluminium sheet and evaluated the mechanical properties of the joint through a single lap shear test. The undercut is the critical parameter that affects the performance of composite clinched joint due to drawing failure in the mechanical test. Then, Lambiase ${ }^{[17]}$ separately studied the mechanical riveting connection performance of different thermoplastic polymers and aluminium alloy sheet and successfully realized the clinching of non-metal and aluminium alloy. Vahid et al. ${ }^{[18]}$ introduced a kind of high-speed mechanical riveting (HSMC). The high speed of the punch is provided by 
releasing electric energy in the fluid during the electro-hydraulic forming process. The technology successfully connects 1050 aluminium alloy and AISI1070 carbon steel, and the mechanical properties of the joint are measured under three kinds of lapping modes, which provides a reference for the development of new technology of dissimilar material connection.

The numerical simulation provides conditions for further study of clinching. By simplifying the actual forming process of the clinched joint, the forming prediction is realized by using finite element software, and the influence of process parameters on the clinched joint is analyzed. Effectively shorten the product development cycle, save material and financial resources. In addition, it can save many mould manufacturing costs. Therefore, the numerical simulation method is more and more widely used in clinching. Ge and Xia ${ }^{[19]}$ prepared different lap specimens for $d x 51 d+Z$ steel and $5182-0$ aluminium alloy, and carried out quasi-static and low-velocity impact tests on riveted joints with peel specimens and shear specimens, respectively. The influence of loading rate on the overall force-displacement response and failure mode of the joint is analyzed by experiment and simulation. He et al. ${ }^{[20]}$ used the finite element method to simulate the clinched process of the telescopic die. The deformation and failure of the clinched joint of the telescopic die under uniaxial tensile load were studied, and the strength and energy absorption of the joint was analyzed. With the application of clinched joint more and more widely [21], some scholars have carried out many numerical simulation research on flat pressing reshaping connection process. After reshaping, the tensile shear strength and energy absorption of the clinched joint are significantly improved. First, numerical simulation research on the shaping method to reduce the protruding height ${ }^{[22]}$ of riveted joint and effectively simulated the joint deformation in the shaping process. Then Chen et al. ${ }^{[23]}$ compared the forming quality of the joint with and without rivets by numerical simulation. The joint with rivets have higher strength and better connection quality. Coppieters et al. ${ }^{[24]}$ predicted the shear and drawing strength of the joint by numerical simulation, and the simulation results were in good agreement with the actual measurement. Tenorio et al. ${ }^{[25]}$ used the finite element method to study the clinching and analyzed the influence of different die shapes on the forming results. The comparison error between the numerical simulation results and the experimental measurement is small, which avoids the manufacturing of different dies and multiple tests. Josip et al. [26] carried out the finite element numerical simulation of the mechanical clinched process of hc260y steel sheet and determined the die parameters with the most significant interlocking influence between sheets. Mucha ${ }^{[27]}$ studied the influence of process parameters on the bonding properties of high strength steel by finite element analysis method, and determined that die radius, die depth and die groove shape have an essential influence on the bonding properties of h320la high strength steel. It is still difficult to connect aluminium alloy and other materials to high strength / low plasticity materials by joining methods based on forming technology. Lee et al. ${ }^{[28]}$ developed a new joining process for these materials combination, namely the flat hole riveting process. Through experiment and simulation, aluminium alloy and high strength material are successfully connected. Wen et al. ${ }^{[29]}$ verified the practicability of flat hole clinching through finite element analysis and experiment. Breda et al. ${ }^{\left[{ }^{[0]}\right.}$ used uncoupled plastic behaviour to 
simulate the plastic properties of clinched joints and studied the properties of clinched joints through simulation and tension shear tests.

The above research shows that the numerical simulation can effectively predict the forming process of clinching. It can save the cost of mold manufacturing when the process parameters change. It provides guidance and reference for practical production. For the sake of effectively predict the clinched forming process of high-strength steel and aluminum alloy heterogeneous materials. In this paper, the clinching of a heterogeneous metal sheet based on the fixed die is studied. Combined with experiment and numerical simulation, the effects of process parameters such as punch radius, punch fillet, die radius, die depth, and forming force on neck thickness, interlock value, bottom thickness, and the neck-lock ratio of steel aluminum clinched joint were studied. Tensile and shear tests analyzed the strength of the upper steellower aluminum joint. The relationship between neck-lock ratio and Maximum tensile and shear strength of joint was obtained. Then the selection strategy of clinched process parameters is analyzed. The numerical simulation of clinched joint forming was studied. The forming quality of the joint with different process parameters was predicted. The problem of frequent processing and manufacturing of mold is solved.

\section{Forming Technology Of The Clinching 2.1 Forming principle}

The clinching is a kind of cold extrusion forming technology in which two or more sheets are subjected to an instantly high-strength extrusion through stamping equipment and die, and the material flows laterally, resulting in axial locking between sheets, forming a circular joint. The process is shown in Fig. 1. The technology has the advantages of no auxiliary materials, simple process, clean and environmental protection, no surface damage, and high specific strength of joints.

\subsection{The clinching experiment}

The research is based on the experiment of clinching. As shown in Fig. 2, cec08 floor type punch is selected as the test equipment, which mainly includes gas-liquid force increasing system, pressure switch, footswitch, and dies part. The maximum impact pressure during clinching is set as forming force. The upper sheet is HC340/590DP high strength steel, and the lower sheet is 6061-T6-T6 aluminum alloy. The thickness of the steel and aluminum sheet is $1.2 \mathrm{~mm}$, and the clinching of upper steel-lower aluminum is collectively referred to as US2-LA2, in which 2 means the thickness of the sheet is $1.2 \mathrm{~mm}$. The stamping speed is about $2 \mathrm{~mm} / \mathrm{s}$. The cut specimen is used to observe the joint section. Single shear lap specimens and cross specimens are used for tension and shear strength tests.

The deformation and flow characteristics of heterogeneous alloy with different lap forms are considered. At present, the diameter of the commonly used clinched joint is $4 \mathrm{~mm}-12 \mathrm{~mm}$. The diameter of the selected die is about $8.4 \mathrm{~mm}$. Generally, the die gap of clinching is $30 \%-60 \%$ of the total sheet thickness. The total thickness of the sheet is $2.4 \mathrm{~mm}$. Therefore, the die clearance should be $0.72-1.44 \mathrm{~mm}$. Nevertheless, the 
too-small gap will make the pressure stress between the dies larger. The more friction. In order to improve the service life of the die and reduce the influence of friction. The radius of the punch is $2.6 \mathrm{~mm}$, the radius of the die is $4.2 \mathrm{~mm}$, and the die clearance is $1.6 \mathrm{~mm}$, which is in line with the normal range (Lee et al., 2010). The fillet radius and draft angle of punch slow down the flow of material and improve the clearance of the neck area; the depth and groove size of the die increases the flow of material.

\subsection{Experiment results}

The test results of the clinching are shown in Fig. 3. The connection quality of steel-aluminum joint under different forming forces is excellent. There are no apparent defects and cracks between the upper and lower sheets.

\section{Numerical Simulation Of Clinching Between High Strength Steel And Aluminum Alloy}

\subsection{Material properties}

6061-T6 aluminum alloy and HC340/590DP cold-rolled dual-phase steel were studied. The thickness of the tensile test piece is $2 \mathrm{~mm}$. WDW-100E microcomputer-controlled electronic universal testing machine is selected as the test equipment. According to the actual deformation rate, the strain rate is $0.05 \mathrm{~s}-1$. The flow stress model fitting results of steel and aluminum materials are shown in Fig. 4. The Voce model describes the stress-strain relationship of the material well. The formula is as follows:

$$
\sigma=\sigma_{\mathrm{s}}+A \cdot\left(1-\mathrm{e}^{-\mathrm{m} \varepsilon_{\mathrm{p}}}\right)
$$

Where $\sigma$ is the flow stress; $\varepsilon_{\mathrm{P}}$ is the equivalent plastic strain; $\sigma_{\mathrm{s}}$ is the material's yield stress; $\mathrm{A}$ and $\mathrm{m}$ are the material parameters.

\subsection{Finite element model}

For the sake of predicting the forming quality of clinched joint, a two-dimensional axisymmetric numerical simulation model of the clinched joint is established by using ABAQUS, as shown in Fig. 5. The critical dimension parameters are neck thickness value $t_{N}$, interlock value $t_{U}$, bottom thickness value $d$, and neck-lock ratio c. Since clinched forming is a quasi-static analysis process, the dynamic display method is used for analysis and calculation. The punch, blank holder, and fixed die are set as rigid bodies, and the upper and lower sheets are set as plastic deformation bodies. The grid cell type of sheet is cax4r. ALE adaptive technology is used to improve the mesh distortion caused by severe extrusion. To ensure consistency with the forming test, the friction coefficient between the upper sheet and the lower sheet is 0.28 . The friction coefficient between die and sheet is 0.12 . The blank holder force is constant at $10 \mathrm{KN}$. The stamping speed is about $2 \mathrm{~mm} / \mathrm{s}$.

\subsection{Simulation results and verification}


The impact force-displacement curve of the joint in the forming process is shown in Fig. 6 . The comparison of numerical simulation and experimental measurement results is shown in Fig. 7. The simulation result of the joint is sound. The prediction error of neck thickness was $2.55 \%$. The prediction error of the interlock value is $3.93 \%$. The simulation model can effectively predict the process of clinching.

\section{The Effects Of Process Parameters On Clinched Joints}

To make the forming quality of clinched joint meet the standard requirements, to ensure the prediction accuracy of joint section size. Based on the simulation data, the deformation of the critical dimensions of the clinched joint section in the pressure holding unloading stage is analyzed. The main process parameters studied are forming force $F_{1}$, blank holder force $F_{2}$, punch radius $R_{P}$, punch fillet $R_{1}$, draft angle $\beta$, die radius $R_{D}$, die depth $H$, and groove width $L$.

In the pressure holding-unloading stage, the neck thickness, interlock value, and bottom thickness of the clinched joint under different process parameters were measured, As shown in Fig. 8. The neck thickness value $t_{N 1}$, interlock value $t_{U 1}$ and bottom thickness value $d_{1}$ were measured in the pressure holding stage, and the neck thickness value $t_{\mathrm{N} 2}$, interlock value $t_{\mathrm{U} 2}$, and bottom thickness value $\mathrm{d}_{2}$ were also measured in the unloading stage. The critical dimension difference between the two stages is the deformation. Set $\mathrm{N}$ value, $\mathrm{U}$ value, and $\mathrm{D}$ value, respectively. It is worth noting that the results after unloading are measured when the effects of forming process parameters, Punch's geometry parameters and die structure parameters on the forming quality of clinched joint are studied.

\subsection{Effects of forming process parameters 4.1.1 Forming force}

Set other process parameters to constant values. The effect of forming force $F_{1}$ on the joint was studied. The forming force was set to $30 \mathrm{KN}, 40 \mathrm{kN}$, and $50 \mathrm{kN}$ for finite element simulation. The results are shown in Fig. 9. With the increase of $F_{1}, t_{N}$ decreased, $t_{U}$ increased, and $c$ decreased. The neck thickness decreases when the initial forming force increases. As the forming force continues to increase, the transverse flow of the material is slow, the deformation increases, and the neck thickness continues to decrease. When the groove is filled, the material is squeezed seriously, and the interlock area increases. The $N_{\max }$ and $U_{\max }$ values after unloading are both 0.005 . The deformation rate is $1.44 \%$ and $1.26 \%$, respectively. The maximum error of $\mathrm{c}$ is $2.4 \%$. The above error is small, and the changing trend is the same in the two stages of pressure holding and unloading. Under different forming forces, the prediction accuracy of numerical simulation is higher.

\subsubsection{Blank holder force}


The blank holder force $F_{2}$ is set to $1 \mathrm{KN}, 5 \mathrm{KN}, 10 \mathrm{KN}, 20 \mathrm{KN}$, and $30 \mathrm{KN}$ for finite element simulation. The results are shown in Fig. 10. With the increase of $F_{2}, t_{N}$ increases slightly and then tends to be constant. The variation of the whole process is slight; $t_{U}$ first decreases, increases, and finally tends to be constant. The change's fluctuation was also slight; the change amplitude of $c$ was unstable in the two stages, and the ratio was always greater than 1 . $d$ fluctuates slightly with the increase of $F_{2}$. In a specific range, $F_{2}$ has little influence on the critical dimension parameters of the formed joint. $F_{2}$ can be taken within the acceptable range, but it should not be too large or too small. If $F_{2}$ is too large, the sheet near the joint will be depressed; if $F_{2}$ is too small, the sheet will be warped. The $\mathrm{N}_{\max }$ and $\mathrm{U}_{\max }$ values after unloading are 0.008 and 0.0085 , respectively. The deformation rate is $2.13 \%$ and $2.37 \%$, respectively. The maximum error of $\mathrm{c}$ is $3.0 \%$. The above error is small. Moreover, the changing trend of critical dimensions is the same in the two stages of pressure holding and unloading. There was a significant difference in the value of $\mathrm{c}$. However, the blank holder force has little effect on the process, and $\mathrm{F}_{2}$ is not studied deeply.

\subsection{Effects of punch's geometry parameters 4.2.1 Punch radius}

The punch radius $R_{P}$ was set to $2.4 \mathrm{~mm}, 2.5 \mathrm{~mm}, 2.6 \mathrm{~mm}, 2.7 \mathrm{~mm}$, and $2.8 \mathrm{~mm}$, respectively, for finite element simulation. The results are shown in Fig. 11. There was an inverse relationship between the value of neck thickness $t_{N}$ and the value of interlock $t_{U}$. With the increase of $R_{P}, t_{N}$ first decreases and then changes slightly. The $t_{U}$ is on the rise. The $c$ showed a downward trend. The neck region will decrease when the $R_{p}$ increases initially. With the increase of $R_{p}$, the material flows slowly, the extrusion force increases, and the neck thickness changes little. When the groove is filled, the material is squeezed seriously, and the interlock area increases. The $\mathrm{N}_{\max }$ and $\mathrm{U}_{\max }$ values after unloading are 0.005 and 0.01 , respectively, the deformation rate is $1.48 \%$ and $2.21 \%$, and the maximum error of $c$ is $3.1 \%$. The changing trend of critical dimensions and the neck-lock ratio is the same in the two stages of pressure holding and unloading.

\subsubsection{Punch fillet}

The punch fillet $R_{1}$ is set at $0.1 \mathrm{~mm}, 0.2 \mathrm{~mm}, 0.3 \mathrm{~mm}, 0.4 \mathrm{~mm}$, and $0.5 \mathrm{~mm}$, respectively, for finite element simulation, and the results are shown in Fig. 12. There was an apparent inverse proportional relationship between the value of $t_{N}$ and the value of $t_{U}$, with the increase of $R_{1}, t_{N}$ increases, and $t_{U}$ decreases. Moreover, the change of them is noticeable. $C$ showed an upward trend. The increase of punch fillet will lead to insufficient material flow into the die, slow transverse flow, and low interlock value. The $\mathrm{N}_{\max }$ and $U_{\max }$ values after unloading are 0.005 and 0.004 , respectively, the deformation rate is $1.21 \%$ and $1.74 \%$, and the maximum error of $\mathrm{c}$ is $0.71 \%$. The changing trend of critical dimensions and the neck-lock ratio is the same in the two stages of pressure holding and unloading.

\subsubsection{Draft angle}


The draft angle $\beta$ is set as $0^{\circ}, 0.5^{\circ}, 1^{\circ}, 1.5^{\circ}$, and $2^{\circ}$ respectively for finite element simulation, and the results are shown in Fig. 13. With the increase of $\beta, t_{N}$ first increases, decreases, and then increases, but the change range is small, while $t_{U}$ has been declining, and $c$ has been increasing. Appropriately increasing the draft angle can coordinate the neck thickness and interlock value and improve the clearance of the neck region. After unloading, the $\mathrm{N}_{\max }$ and $\mathrm{U}_{\max }$ values are 0.005 and 0.006 , respectively, and the deformation rate is $1.48 \%$ and $1.54 \%$, and the maximum error of $\mathrm{c}$ is $1.80 \%$. The changing trend of critical dimensions and the neck-lock ratio is the same in the two stages of pressure holding and unloading.

\subsection{Effects of die's geometry parameters \\ 4.3.1 Die radius}

The die radius $R_{D}$ was set as $4.0 \mathrm{~mm}, 4.1 \mathrm{~mm}, 4.2 \mathrm{~mm}, 4.3 \mathrm{~mm}$, and $4.4 \mathrm{~mm}$, respectively, for finite element simulation. The results are shown in Fig. 14. There was also an inverse relationship between the value of neck thickness $t_{N}$ and interlock $t_{U}$. With the increase of $R_{D}, t_{N}$ first increases, then decreases, and finally shows an upward trend; while $t_{U}$ first decreases, then increases, and finally shows a downward trend; when $R_{D}$ is $4.2 \mathrm{~mm}, c$ decreases slightly and then increases all the time. The increase of die radius will make the cavity volume larger. Then the material flow into the die is not enough, and the neck thickness increases. Furthermore, the extrusion force of the material in the transverse flow becomes smaller. The interlock value decreases. The $\mathrm{N}_{\max }$ and $\mathrm{U}_{\max }$ values after unloading are 0.005 and 0.0053 , respectively, the deformation rate is $1.48 \%$ and $1.32 \%$, and the maximum error of $c$ is $1.9 \%$. The changing trend of critical dimensions and the neck-lock ratio is the same in the two stages of pressure holding and unloading.

\subsubsection{Die depth}

The die depth $\mathrm{H}$ was set to $1.35 \mathrm{~mm}, 1.375 \mathrm{~mm}, 1.40 \mathrm{~mm}, 1.425 \mathrm{~mm}$, and $1.45 \mathrm{~mm}$, respectively, for finite element simulation. The results are shown in Fig. 15. With the increase of $H, t_{N}$ showed a downward trend, while $t_{U}$ changed slightly; $d$ showed an upward trend; $c$ showed a downward trend. With the increase of die depth, the die volume increases. It will result in insufficient material flow into the die. The thickness of the neck increases, and the forming force remains unchanged-the bottom thickness increases. The change range of interlock value is small. The $\mathrm{N}_{\max }$ and $\mathrm{U}_{\max }$ values after unloading are 0.008 and 0.0084 , respectively. The deformation rate is $2.23 \%$ and $2.06 \%$. The maximum error of $\mathrm{c}$ was $1.7 \%$. The changing trend of critical dimensions and the neck-lock ratio is the same in the two stages of pressure holding and unloading.

\subsubsection{Groove width}

The groove width $L$ was set as $1.10 \mathrm{~mm}, 1.15 \mathrm{~mm}, 1.20 \mathrm{~mm}, 1.25 \mathrm{~mm}$, and $1.30 \mathrm{~mm}$, respectively, for finite element simulation. The results are shown in Fig. 16. There was an inverse relationship between the value of neck thickness $t_{N}$ and the value of interlock $t_{U}$. With the increase of $L, t_{N}$ first decreases and then 
increases, while $t_{U}$ changes slightly; $c$ first decreases and then increases slightly. The volume of the cavity increases with the increase of the width of the groove. Then the material flows into the groove sufficiently. The neck thickness decreased. However, the groove width has little effect on the interlock value. The $\mathrm{N}_{\max }$ and $U_{\max }$ values after unloading are 0.005 and 0.0044 , respectively. The deformation rate is $1.48 \%$ and $1.09 \%$. The maximum error of $\mathrm{c}$ was $1.5 \%$. The changing trend of critical dimensions and the neck-lock ratio is the same in the two stages of pressure holding and unloading.

\section{The Clinched Strength Test And Variation Of Neck-lock Ratio 5.1 tension and shear strength test}

Cross tensile and shear tests were used to determine the strength of the joint. The cross tensile test is mainly for the axial tension of the formed joint until failure; the shear test is mainly for the radial tension of the formed joint. The equipment and samples are shown in Fig. 17. The two joints are sheared and stretched with the tensile speed of $2 \mathrm{~mm} / \mathrm{min}$, and the changes of shear force and tensile force are measured. WDW-100E microcomputer-controlled electronic universal testing machine is selected as the test equipment, and the self-designed cross tensile fixture and tensile test fixture are used as the fixture. When the single shear lap sample is sheared, the upper fixture clamps the lower aluminum sheet to fix the sample, and the lower fixture clamps the upper steel sheet to drive it to carry out radial tension the speed of $2 \mathrm{~mm} / \mathrm{min}$. When the cross lap sample is stretched, the upper cross fixture clamps the lower aluminum sheet to fix the sample, and the lower fixture clamps the upper steel sheet to drive it to carry out axial tension at the speed of $2 \mathrm{~mm} / \mathrm{min}$.

\subsection{Results and discussion}

To better represent the forming effect of the clinched joint under different process parameters, the ratio parameter of size is used to describe the forming quality of the joint, namely neck-lock ratio $\mathrm{C}$. The formula is as follows:

$$
\mathrm{c}=\frac{\mathrm{t}_{N}}{\mathrm{t}_{U}}
$$

Where $\mathrm{c}$ is the ratio of neck thickness to interlock value, when $\mathrm{c}$ is greater than 1 , neck thickness is more significant than interlock value. When $\mathrm{c}$ is less than 1, neck thickness is less than the interlock value. Figure 4.18 (a) and (b) show the variation of neck-lock ratio and tensile shear strength under different

forming forces. When neck-lock ratio $\mathrm{c}$ is less than 1 , the tensile shear strength decreases monotonously. When the neck-lock ratio is greater than 1 , the tensile shear strength is lower than that when the neck-lock ratio is less than one and closest to 1 . Therefore, when the forming force is variable and the c value is less than one and closest to 1 , the joint strength and forming quality are the best.

\subsection{The design strategy of process parameters}


Take the process parameters selected in this paper as an example. The selection rules of each parameter are analyzed, as shown in Fig. 19. Determine the selection strategy and method. The best combination of process parameters was obtained. For the sake of obtaining a high-quality clinched joint. The specific steps are as follows:

\section{(1) Forming process parameters}

The forming process parameters mentioned in this paper mainly include forming force and blank holder force. According to the test verification, the joint with neck-lock ratio $\mathrm{c}$ less than one and close to 1 has the highest connection strength. Therefore, the best choice of forming force is about $32.5 \mathrm{KN}-40 \mathrm{KN}$; and the blank holder force has little influence on the critical dimension parameters of this process. There was no regular change of neck-lock ratio. Therefore, it is not necessary to discuss the blank holder force, choose the appropriate one.

\section{(2) Punch's geometry parameters}

Punch's geometry parameters mainly include punch radius, punch fillet, and draft angle. According to the selection experience of forming force, there are mainly punch radius of $2.5 \mathrm{~mm}$ and $2.6 \mathrm{~mm}$ near the guideline with neck-lock ratio $c$ of 1 . Therefore, the selection range of punch radius is about $2.5-2.6 \mathrm{~mm}$, according to the variation of neck-lock ratio. The selection range of punch fillet is $0.2-0.3 \mathrm{~mm}$; the broad range of die draft angle is $0-2^{\circ}$, according to the variation of neck-lock ratio with different draft angles. The ratio at $0.5^{\circ}$ or $2^{\circ}$ is close to 1 . Therefore, the range is $0.5-2$ degrees.

\section{(3) Die's geometry parameters}

The Die's geometry parameters include die radius, die depth, and groove width. According to the change curve of neck-lock ratio with different die radius. When the die radius is $4.1 \mathrm{~mm}$, the neck-lock ratio $\mathrm{c}$ is less than one and the closest to 1 . Therefore, the selection range of die radius is about $4.1 \mathrm{~mm}$. Simultaneously, considering whether the die gap is appropriate, the selection range of die depth is about 1.35 or 1.4 , and the neck-lock ratio is the best when the groove width is $1.1 \mathrm{~mm}$.

The selection of the above process parameters is only a selection strategy and reference. Also, according to the actual demand and punch and die structure adjustment.

\section{Conclusion}

Based on the established simulation model of the process of clinching for steel aluminum heterogeneous materials. Different process parameters are selected. For example, forming process parameters, punch geometry parameters, and concave die structural parameters. The influence of different process parameters on the forming quality of joints is studied. Numerical simulation results expound the change rule of the critical dimension of the joint section informing the process. The forming law of the joint under different technological parameters is analyzed. Finally, the relationship between the neck-lock ratio and 
tensile strength and shear strength of the joint under different forming forces is analyzed. The results show that:

(1) According to the comparison of numerical simulation and experimental results. The validity of the numerical model is verified. The error of critical dimensions is less than $5 \%$. Then the influence of process parameters on the forming quality of the joint is studied. With the increasing forming force, the transverse flow of materials is slow. The compression degree increased, and the neck thickness continued to be small. When the groove is filled, the material is squeezed seriously, the interlock area increases, and the blank pressing force has little influence on the critical dimension parameters of the forming joint in a particular range;

(2) With the increase of the radius of the punch, the material flow is slow. The extrusion pressure increases, and the neck thickness changes little. When the groove is filled, the material is squeezed seriously, and the interlock value increases; the increase of the fillet of the punch will lead to the defective material flowing into the concave die. The material flow is slow in the transverse direction. The interlock value is small, and the proper increase of the draft angle can coordinate the neck thickness and interlock value and improve the gap in the neck area;

(3) The increase of die radius will make the cavity volume more significant, and then the material will not flow into the die. The neck thickness increased. Furthermore, the extrusion force of the material in the transverse flow becomes smaller. The interlock value is reduced; Too large or too small, the die depth will cause stress concentration in the neck area. Therefore, under the condition of other conditions, the thickness of the bottom can be adjusted by selecting the appropriate depth of the die, and the increase of the groove width will make the volume of the groove cavity larger. Then the material flows into the groove sufficiently. The neck thickness decreased. However, the groove width has little effect on the interlock value.

(4) Finally, the change law of the critical dimension of the joint section in the pressure retaining unloading stage is analyzed. The results show that the clinched joint's neck thickness and interlock value with different parameters are obtained. The deformation rate is lower than $5 \%$. The error of the ratio of necklock is less than $5 \%$, so the deformation of the heterogeneous material in the clinching during the pressure retaining unloading stage has little influence on the forming quality of the joint. The accuracy of numerical simulation is also verified indirectly.

(5) When the ratio of neck-lock $\mathrm{c}$ is less than 1, the tensile strength and shear strength decrease monotonously. The tensile and shear strength of the neck-lock ratio greater than 1 is lower than that of the one closest to 1 . When the forming force is variable, when the $c$ value is less than one and the closest to 1 , the clinched joint is the best, and the forming quality is the best. According to the law, the selection strategy of other process parameters is briefly described.

\section{Declarations}




\section{Acknowledgments}

The authors express thanks to Changchun Schmidt Automation Technology Co.Ltd for providing experiments in the study.

\section{Author contributions}

Qihan Li: methodology, reviewing and editing, project administration. Chuanwei Xu: conceptualization, experiment, writing-original draft preparation. Song Gao: investigation, translate, resources. Fenglei Ma: simulation, review and editing. Qingming Zhao: investigation, validation. Dongwei Gu: investigation, reviewing and editing. Xiaoheng Han: reviewing and editing, supervision.

\section{Funding}

This work was supported by the National Natural Science Foundation of China[No.51805045]; the Scientific and Technological Developing Scheme of Ji Lin Province[No.20190302100GX and No. 20200401115GX].

\section{Availability of Data and Materials}

The data during the current study are available rom the corresponding author on reasonable request.

\section{Conflict of interest}

The authors declare that they have no competing interests.

\section{Ethical approval}

This paper is new. Neither the entire paper nor any part of its content has been published or has been accepted elsewhere. It is not being submitted to any other journal as well.

Consent to participate Not applicable

Consent to publish Not applicable

the percentage of self-citation $\square$ Not yet

No color is used for any number in printing

\section{References}

1. Jambhale S., Kumar S., Kumar S (2021) Characterization and optimization of flat friction stir spot welding of triple sheet dissimilar aluminium alloy joints. Silicon. 1:1-16.

2. Ang HQ (2021) An overview of self-piercing riveting process with focus on joint failures, corrosion issues and optimisation techniques. Chinese Journal of Mechanical Engineering 34:1-25. 
3. Abe Y, Mori K, Kato T (2012) Joining of high strength steel and aluminium alloy sheets by mechanical clinching with dies for control of metal flow. Journal of Materials Processing Tech 212:884-889.

4. Yohei A, Toru K, Ken-ichiro M, Shoma N (2014) Mechanical clinching of ultra-high strength steel sheets and strength of joints. Journal of Materials Processing Tech 214: 2112-2118.

5. Mostafa K, Sabra A, Mukesh K.J (2017) Die-less clinching process and joint strength of AA7075 aluminum joints. Thin-Walled Structures 120:421-431.

6. Jacek M, Waldemar W (2014) The clinching joints strength analysis in the aspects of changes in the forming technology and load conditions. Thin-Walled Structures 82:55-66.

7. Chao C, Shengdun Z, Xiaolan H, et al. (2017) Investigation of the height-reducing method for clinched joint with AL5052 and AL6061. The International Journal of Advanced Manufacturing Technology 89:2269-2276.

8. Chao C, Xiaolan H, Shengdun Z, Fan X, et al. (2017) Comparative study on two compressing methods of clinched joints with dissimilar aluminum alloy sheets. The International Journal of Advanced Manufacturing Technology 93:1929-1937.

9. Chao C, Shengdun Z, Minchao C, Xiaolan H, et al (2016) An experimental study on the compressing process for joining Al6061 sheets. Thin-Walled Structures 108:56-63.

10. Chao C, Shuqin F, Xiaolan H, Shengdun Z, Minchao C, Tohru I (2017) Experimental study on the height-reduced joints to increase the cross-tensile strength. The International Journal of Advanced Manufacturing Technology 91:2655-2662.

11. Chao C, Shengdun Z, Xiaolan H, Minchao C, Xuzhe Z, Tohru I (2017) Experimental investigation of the mechanical reshaping process for joining aluminum alloy sheets with different thicknesses[J]. Journal of Manufacturing Processes 26:105-112.

12. Chao C, Shengdun Z, Xiaolan H, Minchao C, Shuqin F (2016) Investigation of mechanical behavior of the reshaped joints realized with different reshaping forces. Thin-Walled Structures 107:266-273.

13. Chen S, Ruixiang Y, Chao C, Hao P, Xiangkun R, Shengdun Z (2020) Forming mechanism of the repairing process on clinched joint. Journal of Manufacturing Processes 50:329-335.

14. Chao C, Xiangkun R, Hao P, Huiyang Z, Ruixiang Y, Xiaolan H (2020) Research on the mechanical properties of repaired clinched joints with different forces. Thin-Walled Structures 152:106752.

15. Huang ZQ, Jun Y (2015) Dissimilar joining of aluminum alloy and stainless steel thin sheets by thermally assisted plastic deformation. Journal of Materials Processing Tech 225:393-404.

16. Francesco L, Dae-Cheol K (2016) Feasibility of mechanical clinching for joining aluminum AA6082T6 and Carbon Fiber Reinforced Polymer sheets. Materials\& Design 107:341-352.

17. Francesco L (2015) Joinability of different thermoplastic polymers with aluminium AA6082 sheets by mechanical clinching. The International Journal of Advanced Manufacturing Technology 80:1995-2006. 
18. Babalo V, Fazli A, Soltanpour M (2021) Experimental study of the mechanical performance of the new high-speed mechanical clinching. International Journal of Lightweight Materials and Manufacture 4:218-236.

19. Yulong G, Yong X (2020) Mechanical characterization of a steel-aluminum clinched joint under impact loading. Thin-Walled Structures 151:106759.

20. Xiaocong H, Fulong L, Baoying X, Huiyan Y, Yuqi W, Fengshou G, Andrew B (2014) Numerical and experimental investigations of extensible die clinching. The International Journal of Advanced Manufacturing Technology 74:1229-1236.

21. Chao C, Shengdun Z, Minchao C, Xiaolan H, Xuzhe Z, Tohru I (2017) Effects of geometrical parameters on the strength and energy absorption of the height-reduced joint. The International Journal of Advanced Manufacturing Technology 90:3533-3541.

22. Tong W, Hui W, Chen $Y$, Lantao $L$ (2014) On a reshaping method of clinched joints to reduce the protrusion height. The International Journal of Advanced Manufacturing Technology 71:1709-1715.

23. Chao C, Shengdun Z, Minchao C, Xiaolan H, Ningyu B (2017) Numerical and experimental investigations of the reshaped joints with and without a rivet. The International Journal of Advanced Manufacturing Technology 88:2039-2051.

24. Sam C, Steven C, Pascal L, Hugo S, Paul V H, Dimitri D (2011) Reproducing the experimental pull-out and shear strength of clinched sheet metal connections using FEA. International Journal of Material Forming 4:429-440.

25. Marcio BT, Sergio FL, Manolo LG, Paulo VPM (2019) The influence of tool geometry and process parameters on joined sheets by clinching. Journal of the Brazilian Society of Mechanical Sciences and Engineering 41:49-55.

26. Cumin J, Stoić A, Duspara M, Samardžić I (2019) FEM Numerical Simulations of the Mechanical Clinching Process of HC260Y Steel. Tehnički vjesnik 26:4943-4954.

27. Jacek M (2011) The analysis of lock forming mechanism in the clinching joint. Materials\& Design 32:4943-4954.

28. Lee C J, Lee J M, Ryu H Y, et al (2014) Design of hole-clinching process for joining of dissimilar materials-Al6061-T4 alloy with DP780 steel, hot-pressed 22MnB5 steel, and carbon fiber reinforced plastic. Journal of Materials Processing Tech 214:2169-2178.

29. Tong W, Qian H, Qing L, Wenxue O, Suo Z (2016) Joining different metallic sheets without protrusion by flat hole clinching process. The International Journal of Advanced Manufacturing Technology 85:217-225.

30. Andreas B, Sam C, Dimitri D (2017) Equivalent modelling strategy for a clinched joint using a simple calibration method. Thin-Walled Structures 113:1-12.

\section{Figures}




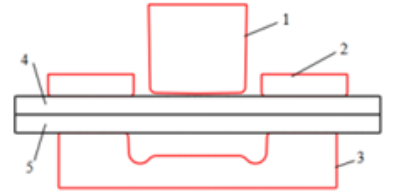

(a)

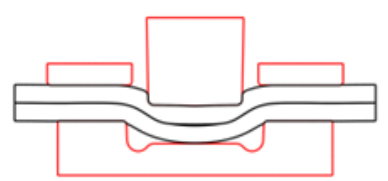

(b)

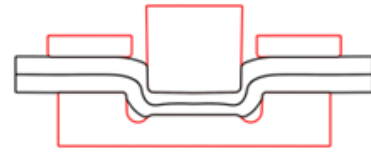

(c)

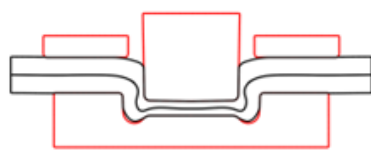

(d)

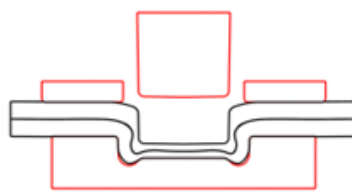

(e)

Figure 1

Forming process principle of clinched joints(1: punch; 2: blank holder; 3:die; 4: upper sheet; 5: lower sheet)
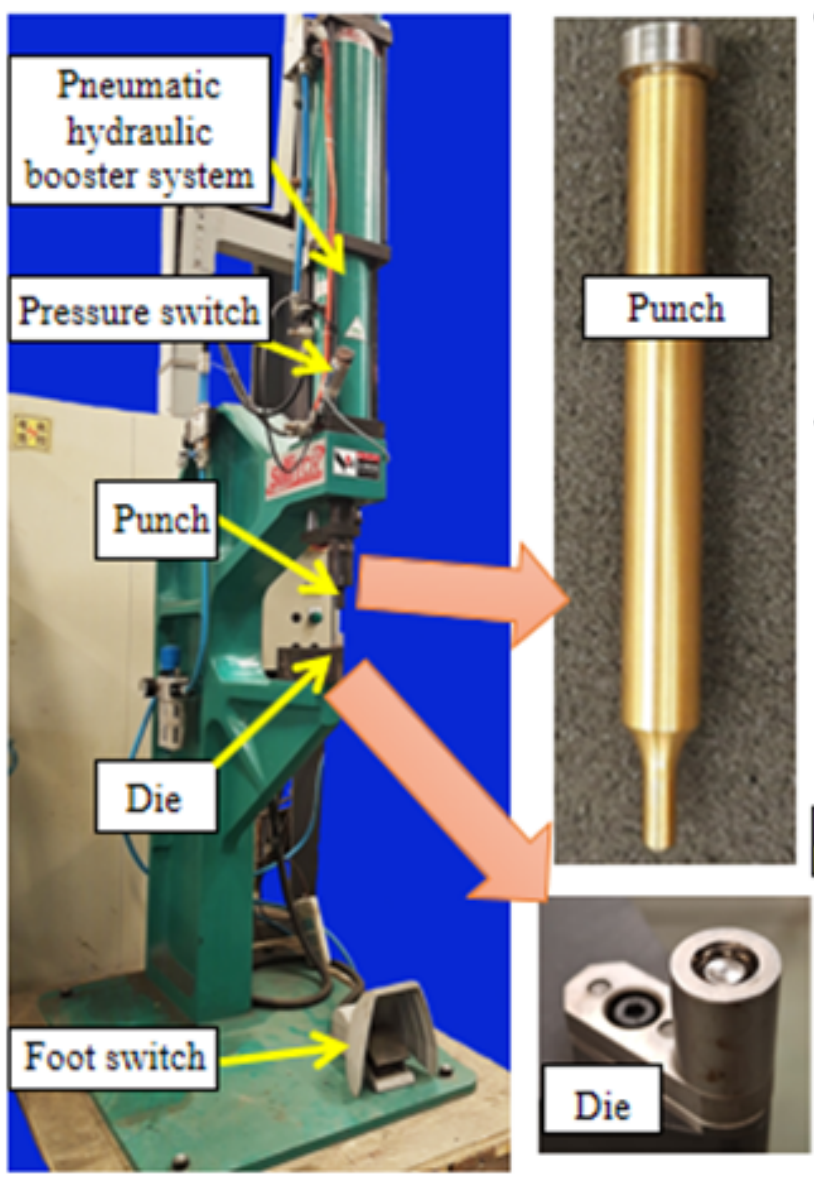

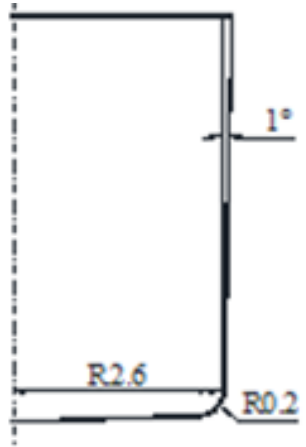

Punch size
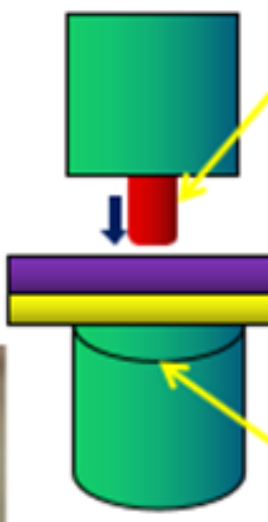

Cutting sample

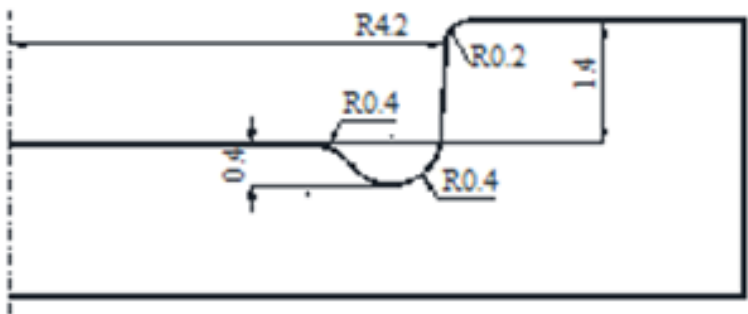

Die size

\section{Figure 2}

Test equipment and die of clinching

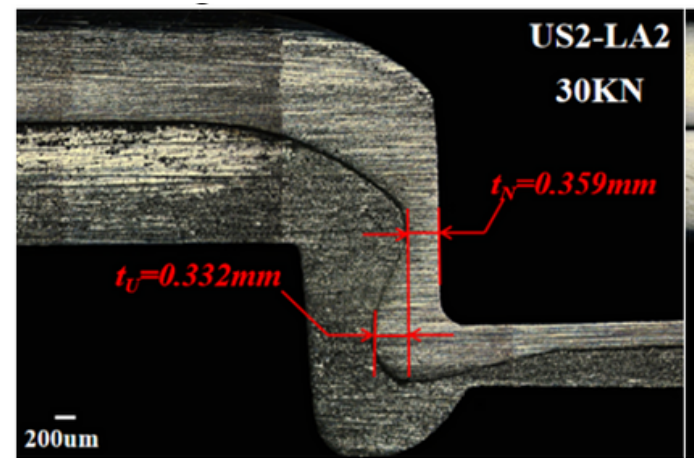

(a) $30 \mathrm{KN}$

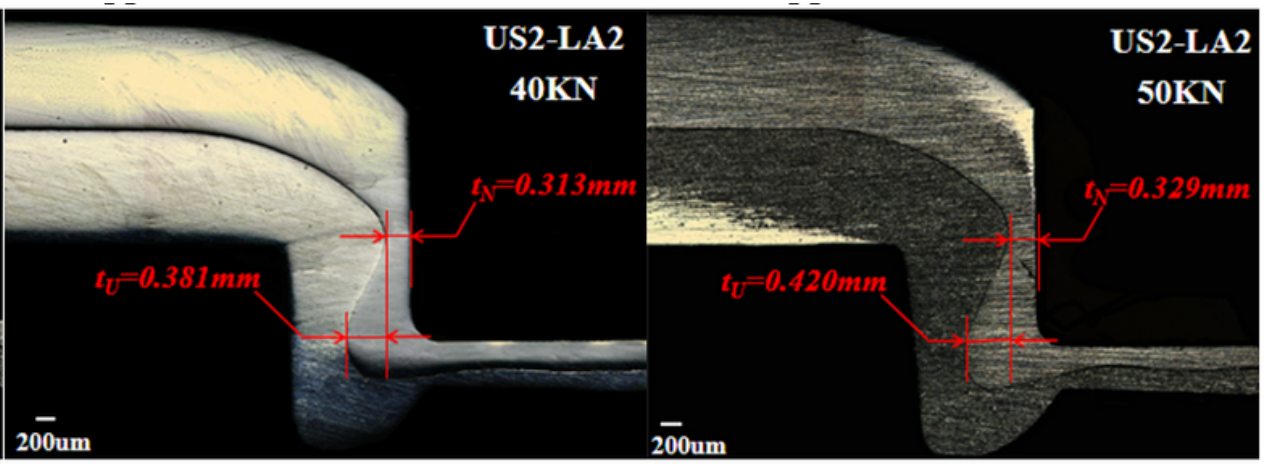

(b) $40 \mathrm{KN}$

(c) $50 \mathrm{KN}$

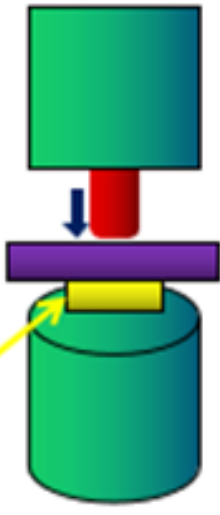

Cross lap specimens

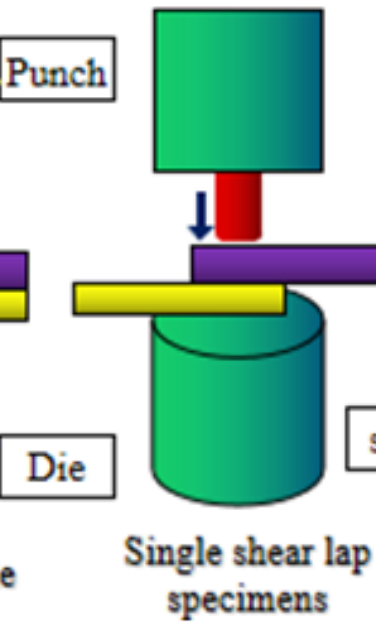

sheets 
Figure 3

Joint section and actual size under different forming forces

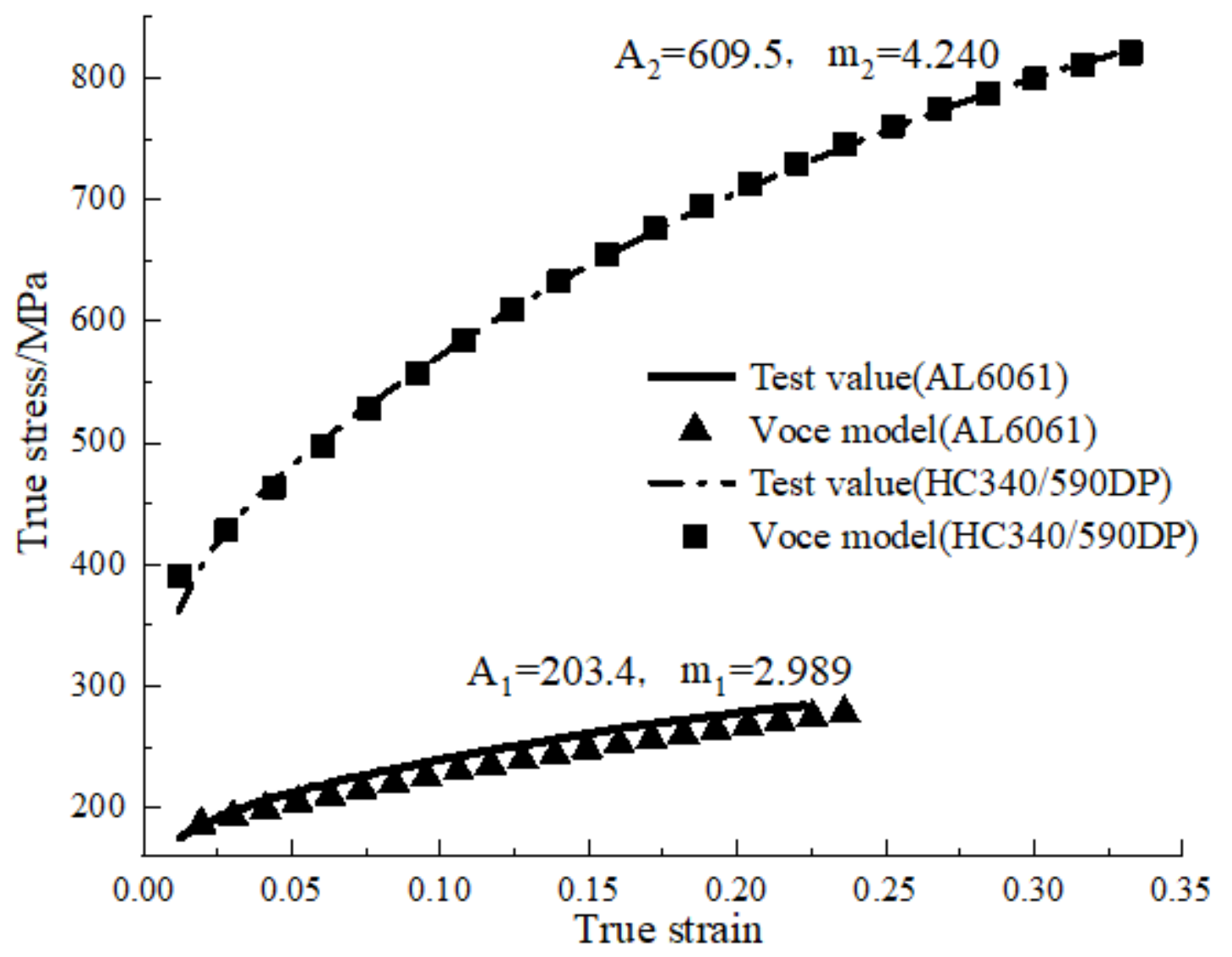

Figure 4

Stress-strain curves of two materials 


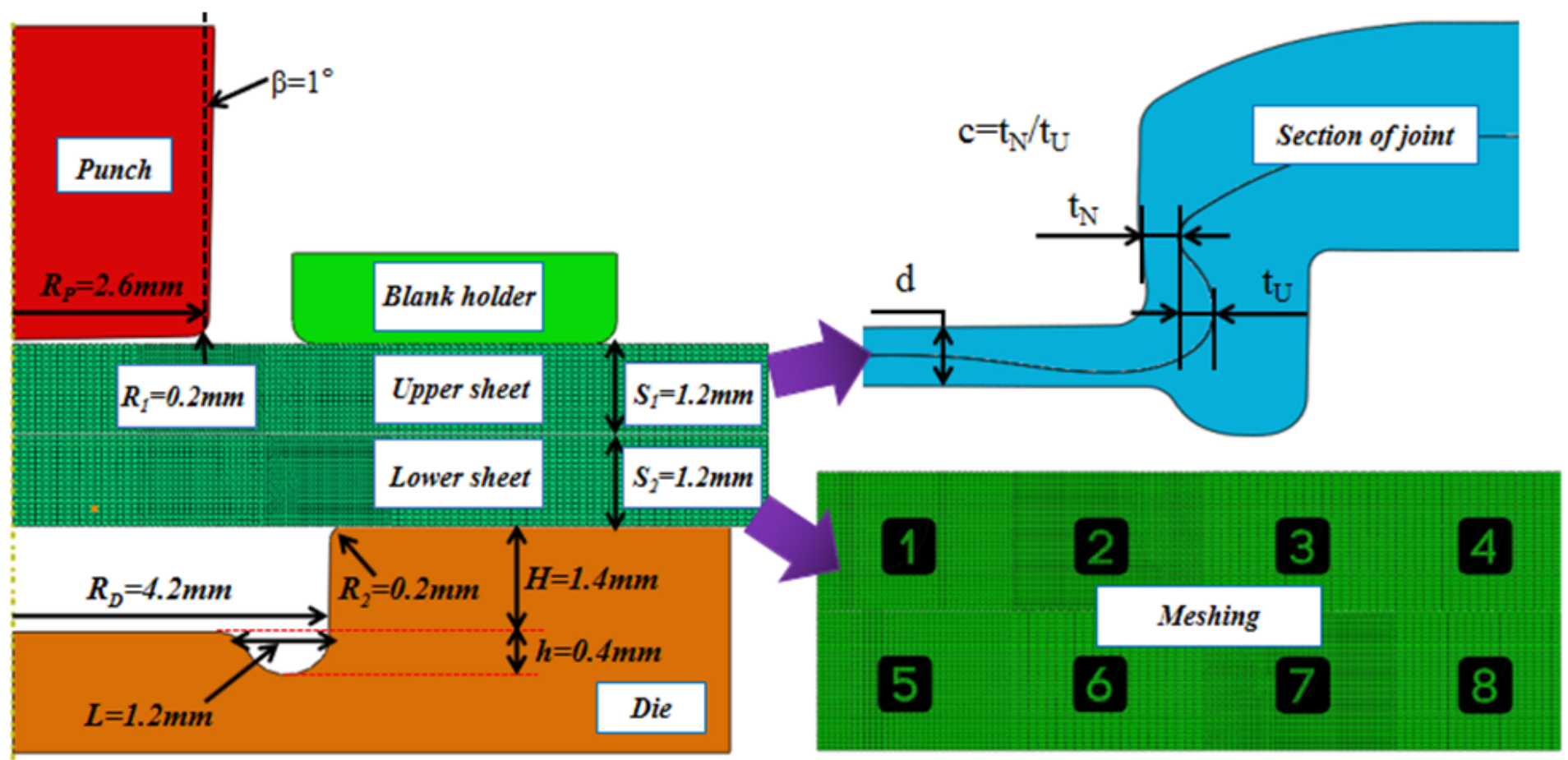

Figure 5

Finite element model and mesh generation of clinching 


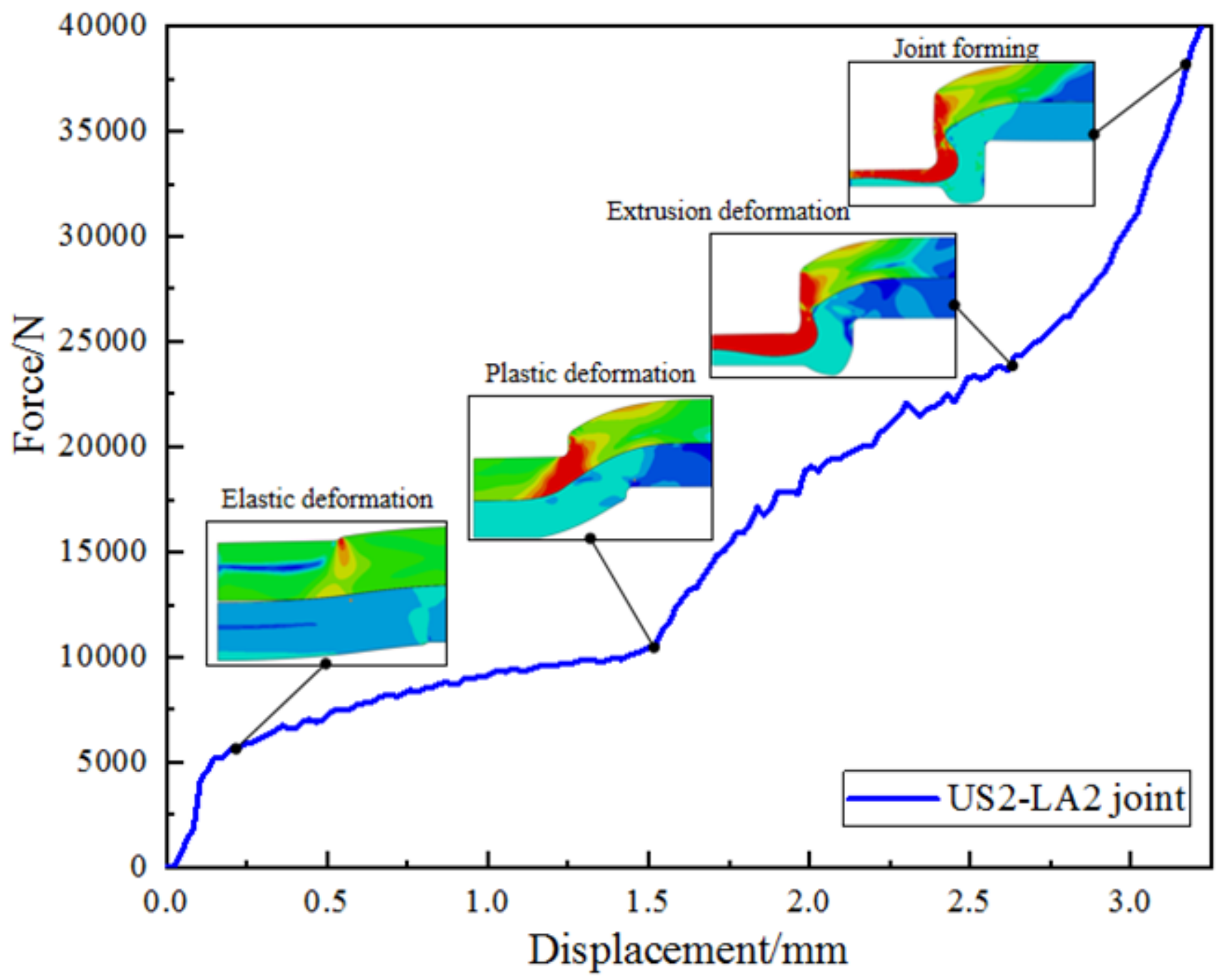

Figure 6

Punching force displacement curve in joint forming process
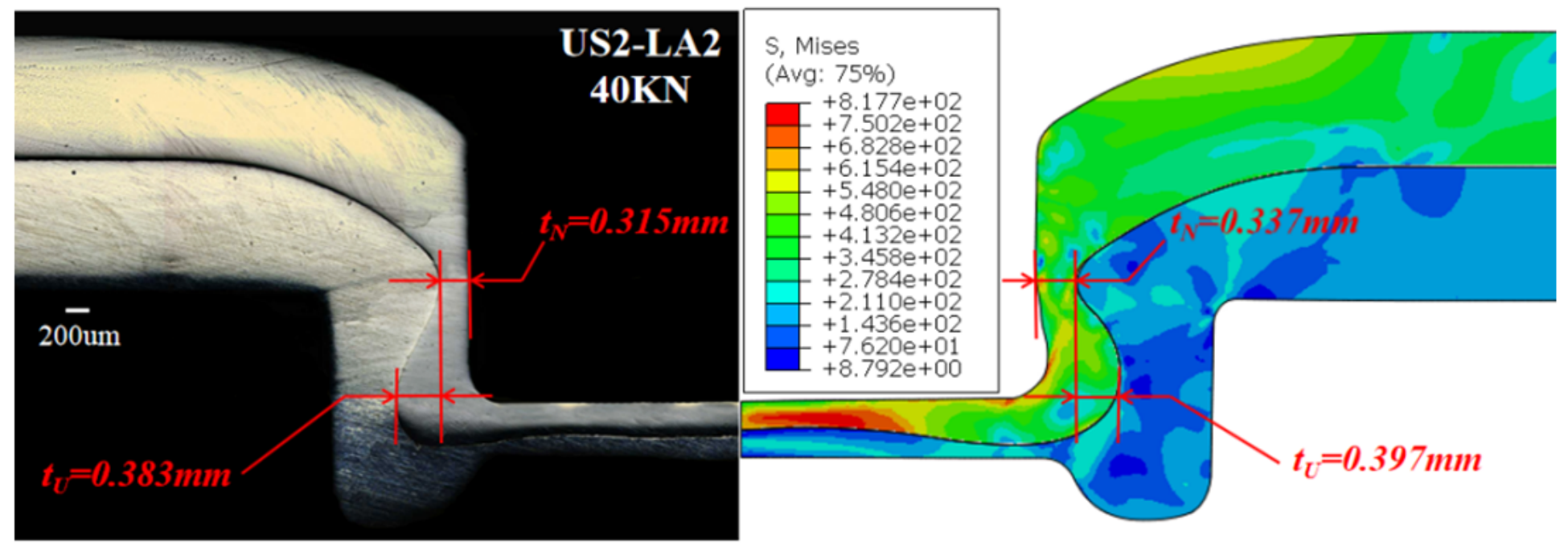

Figure 7 


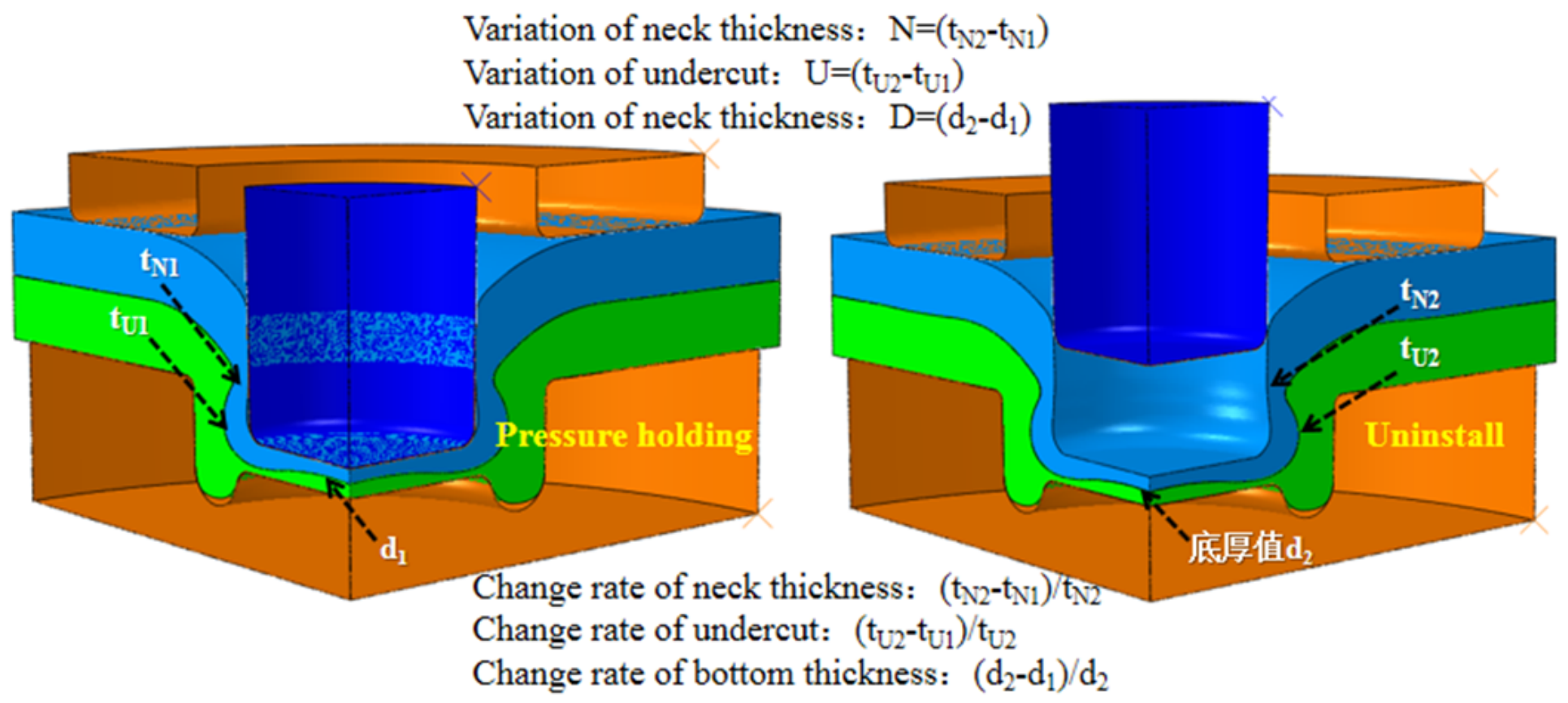

\section{Figure 8}

Analysis of critical dimension change of clinched joint during packing unloading stage

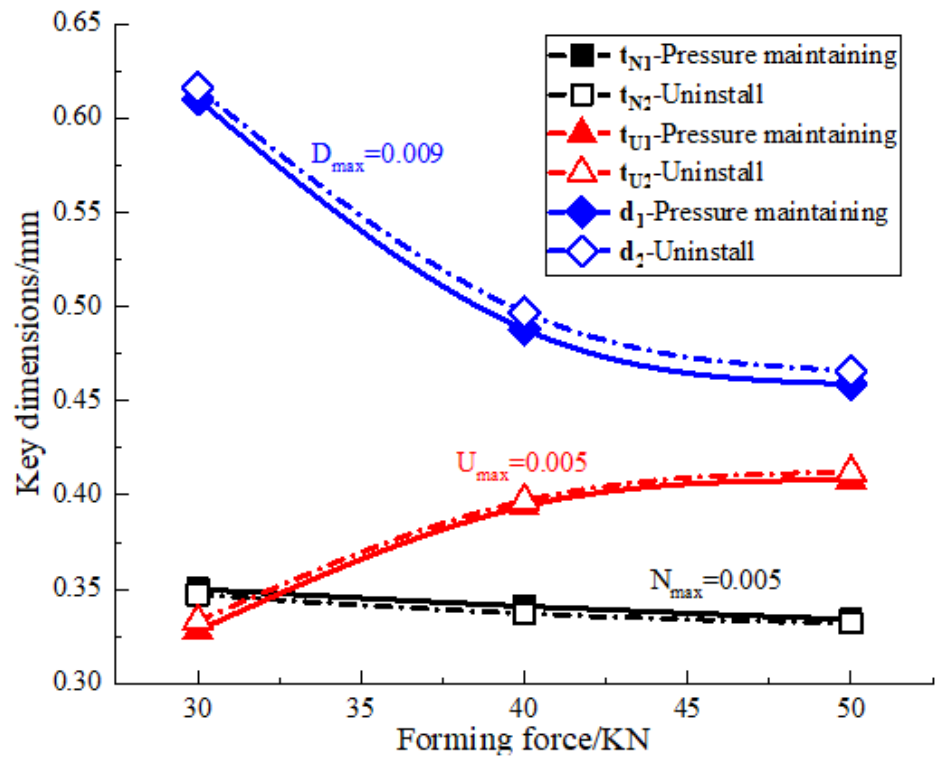

(a) critical dimensions

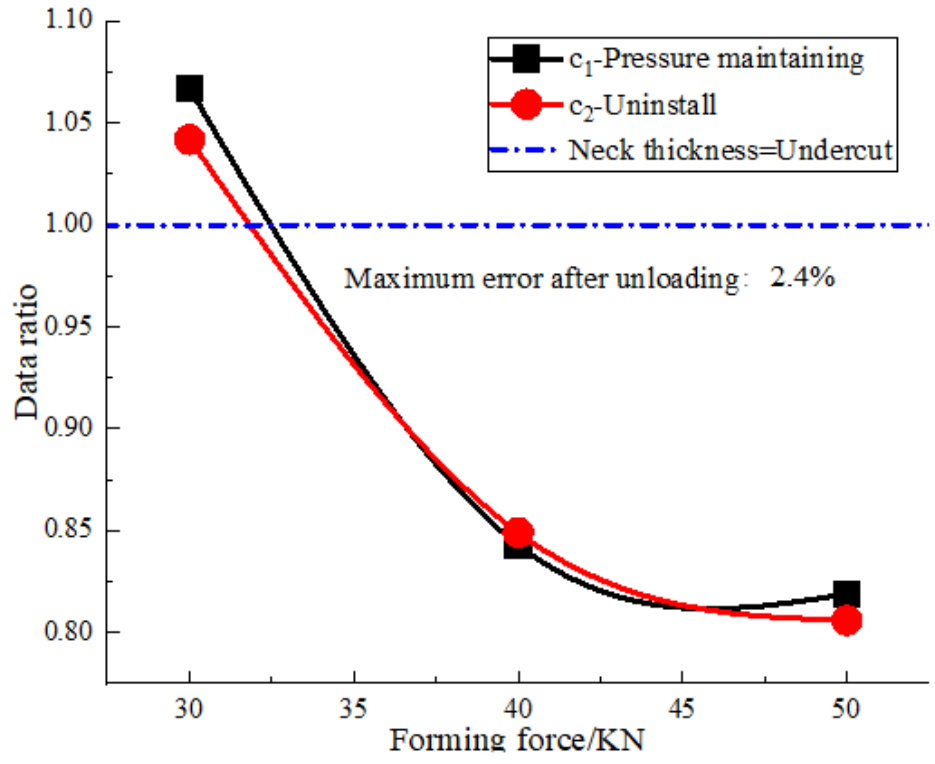

(b) neck-lock ratio

Figure 9

Effect of forming force on joint forming quality 


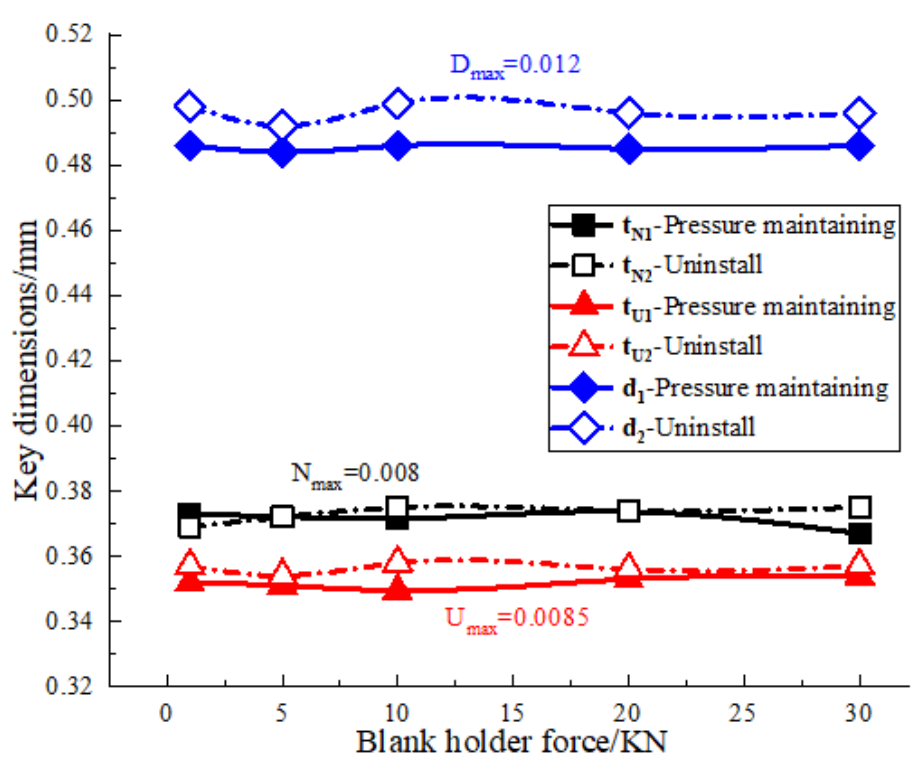

(a) critical dimensions

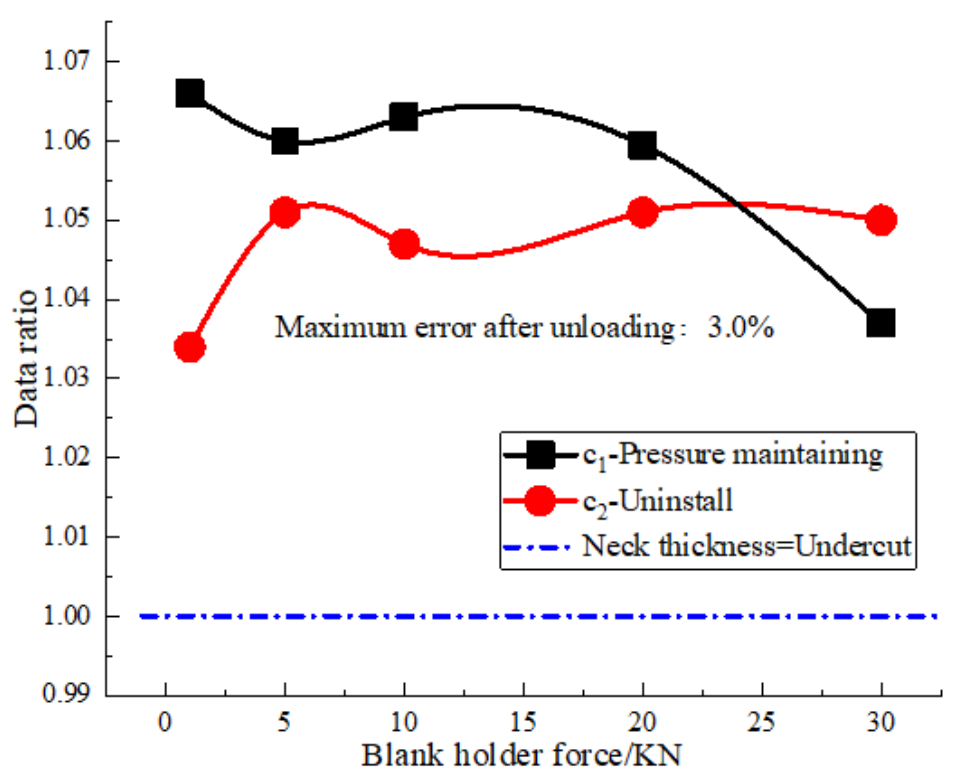

(b) neck-lock ratio

\section{Figure 10}

Effect of blank holder force on forming quality of joint

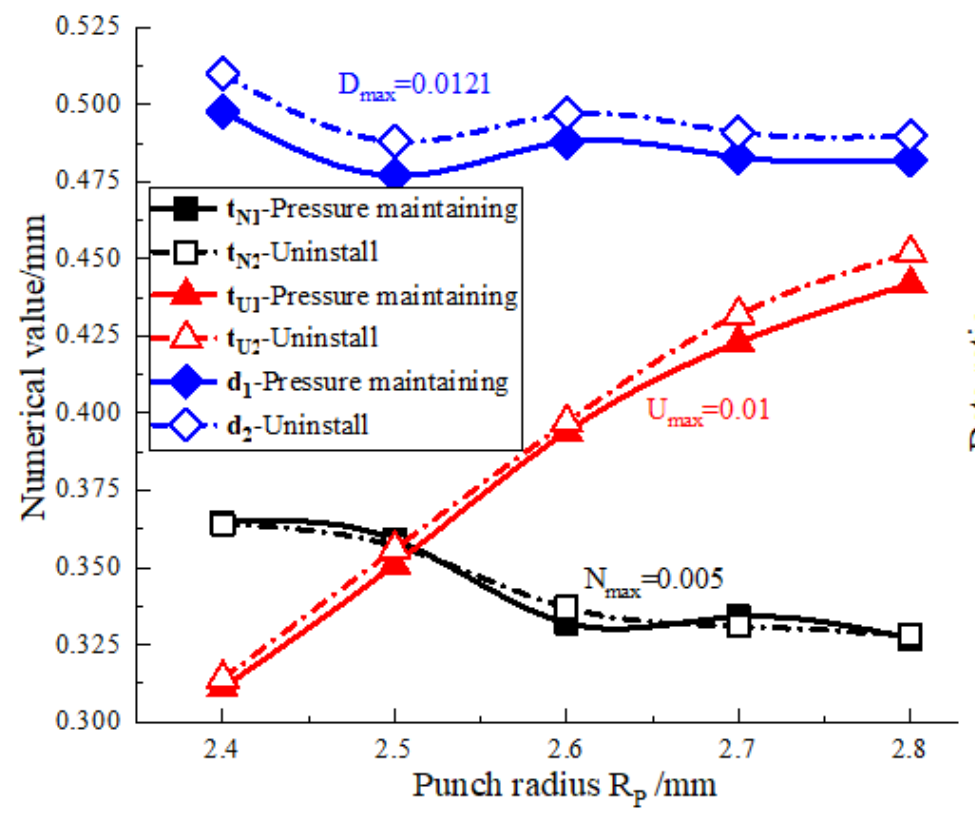

(a) critical dimensions

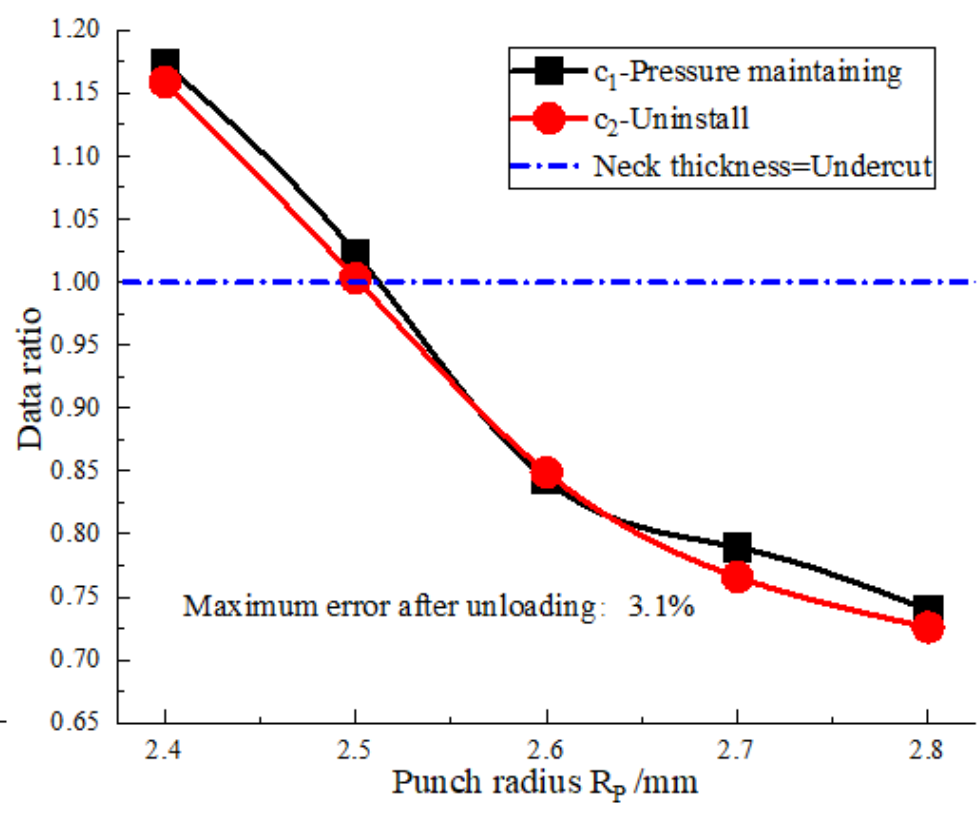

(b) neck-lock ratio

Figure 11

Effect of punch radius on forming quality of joint 


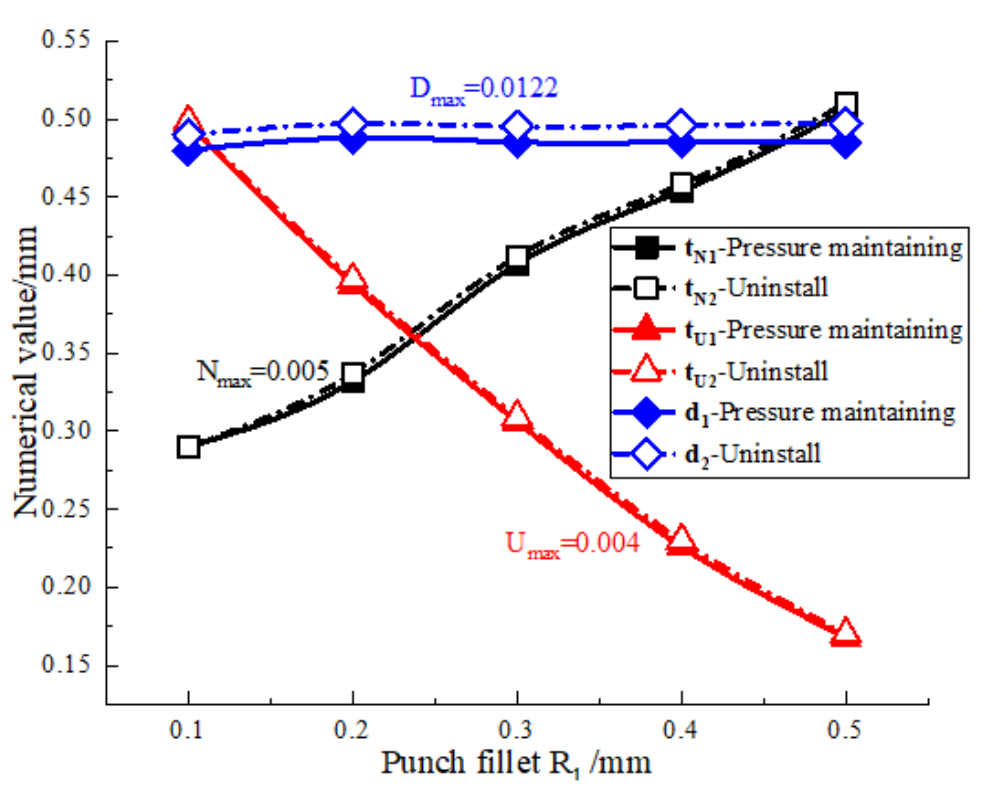

(a) critical dimensions

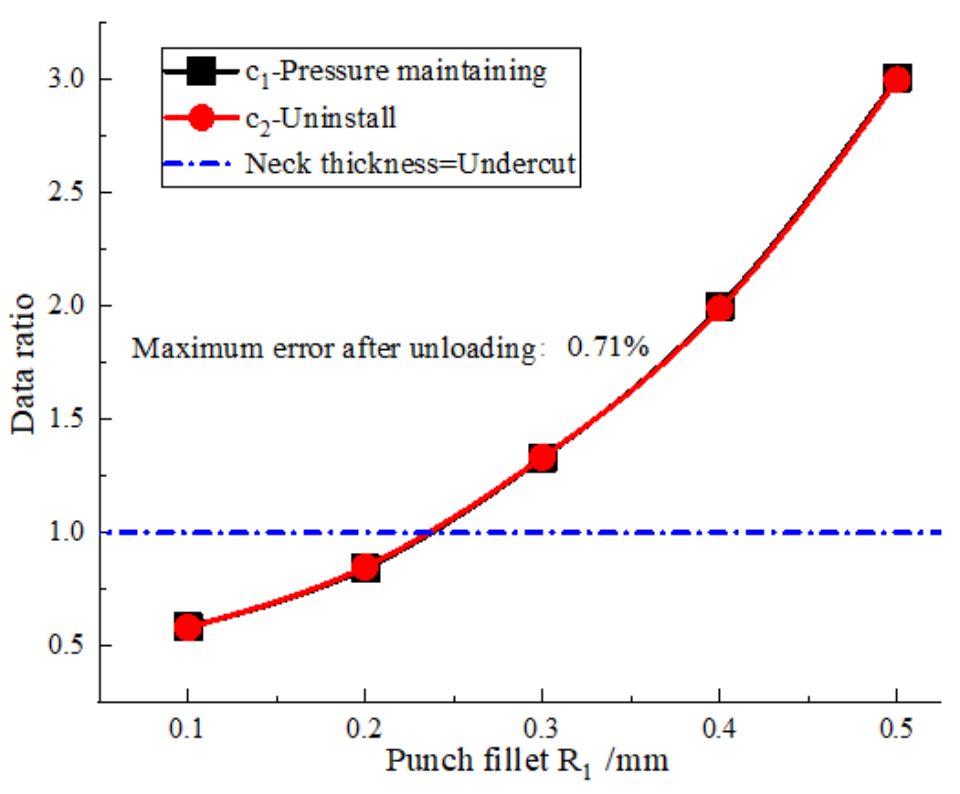

(b) neck-lock ratio

\section{Figure 12}

Effect of punch fillet on forming quality of joint

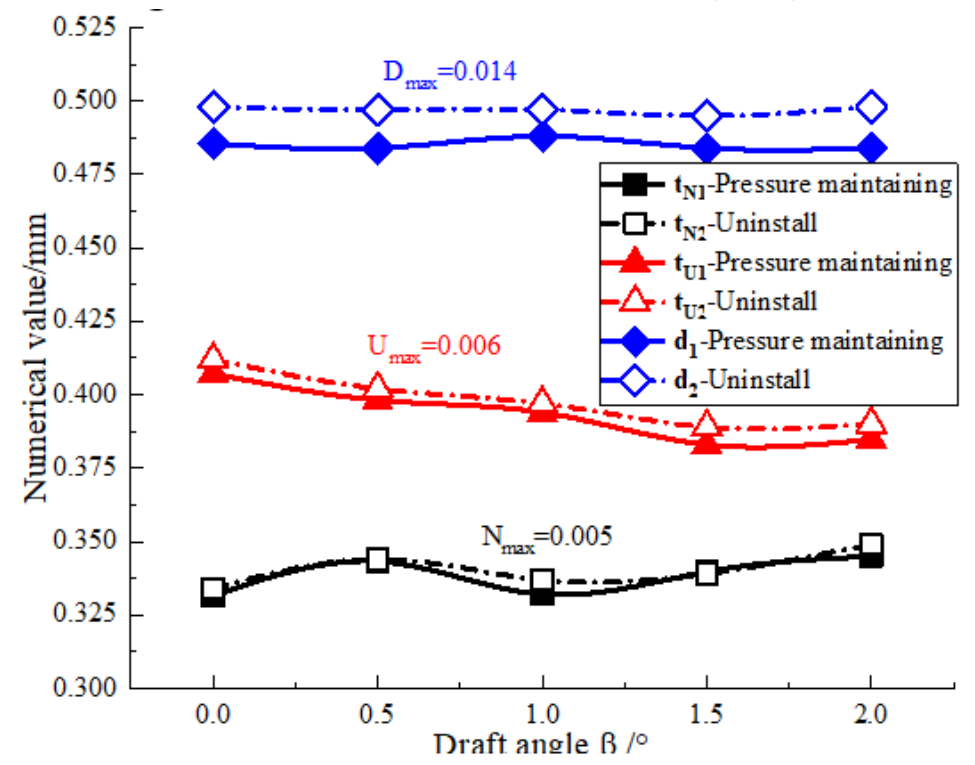

(a) critical dimensions

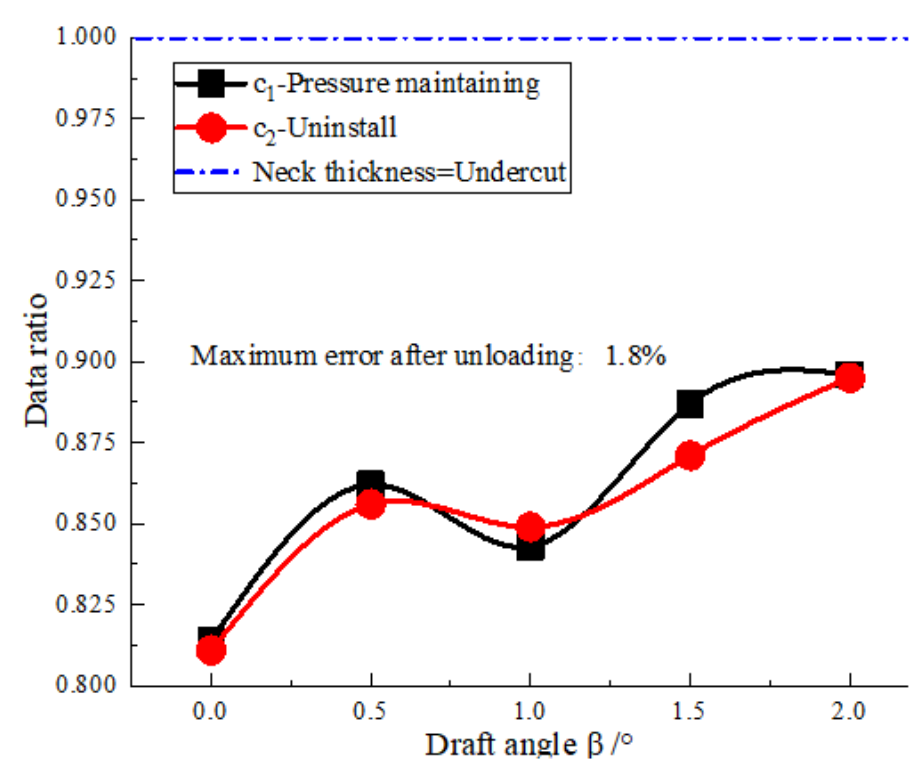

(b) neck-lock ratio

Figure 13

Effect of draft angle on forming quality of joint 


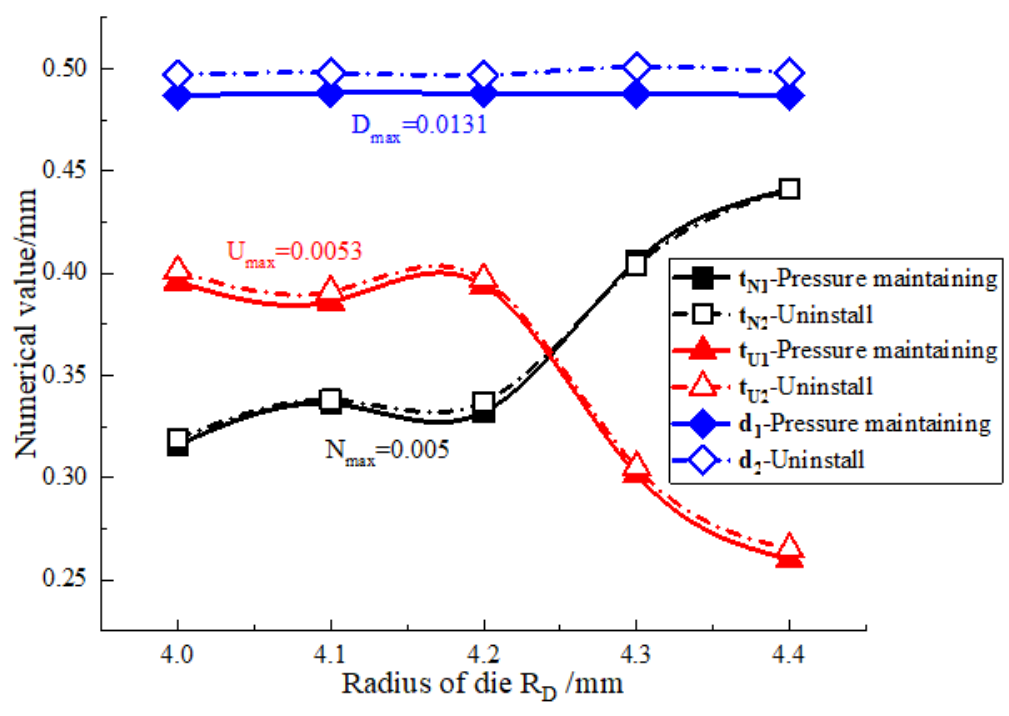

(a) critical dimensions

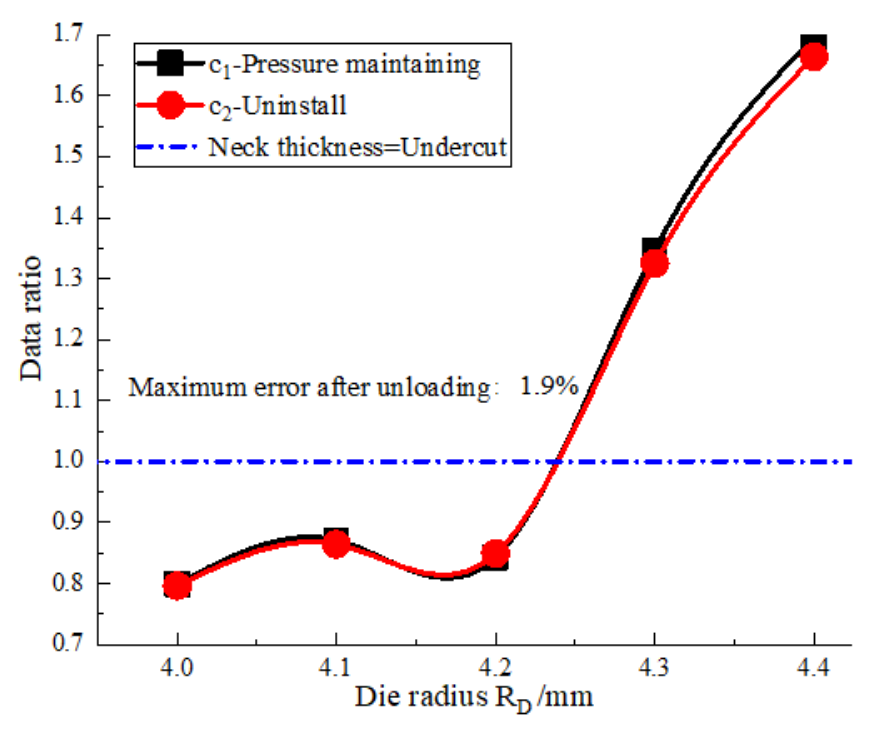

(b) neck-lock ratio

\section{Figure 14}

Effect of die radius on forming quality of joint

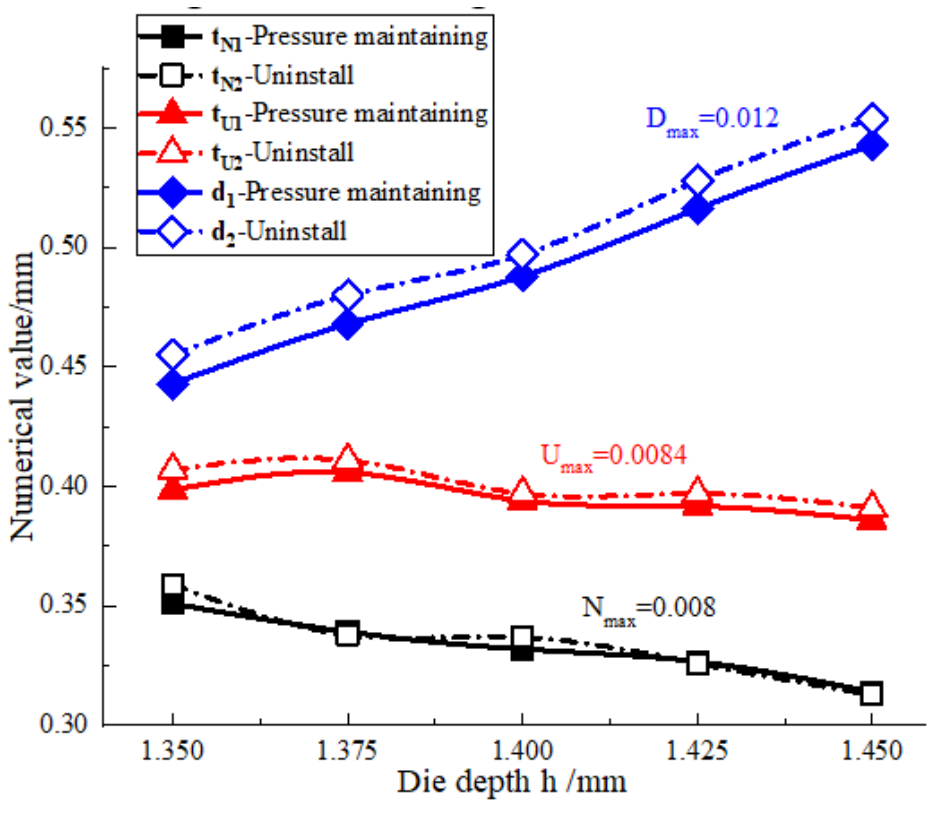

(a) critical dimensions

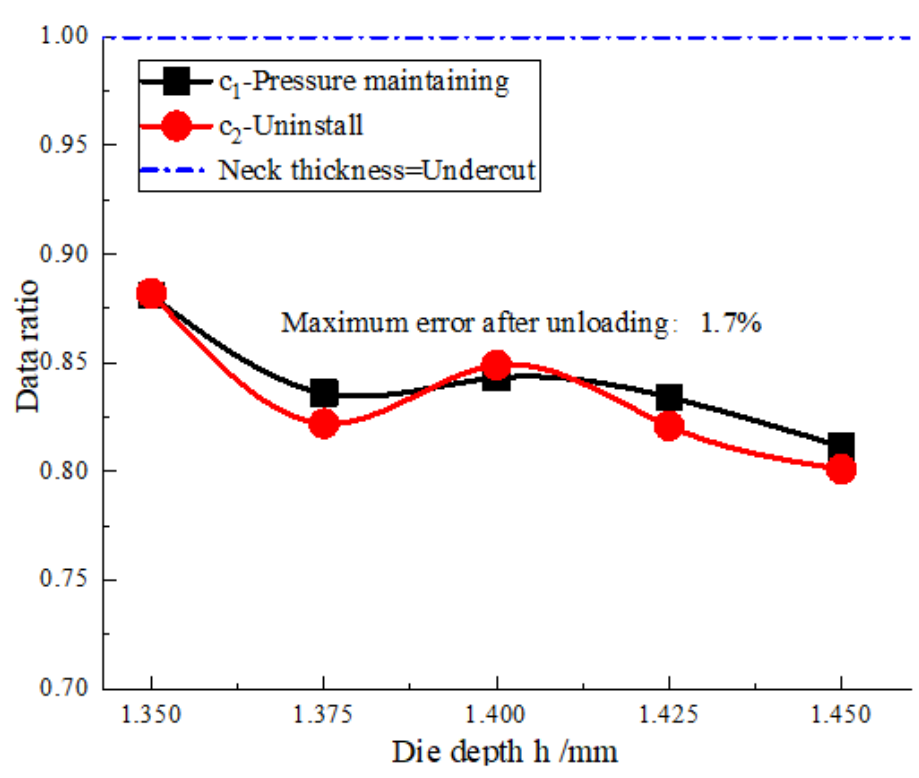

(b) neck-lock ratio

Figure 15

Effect of die depth on forming quality of joint 


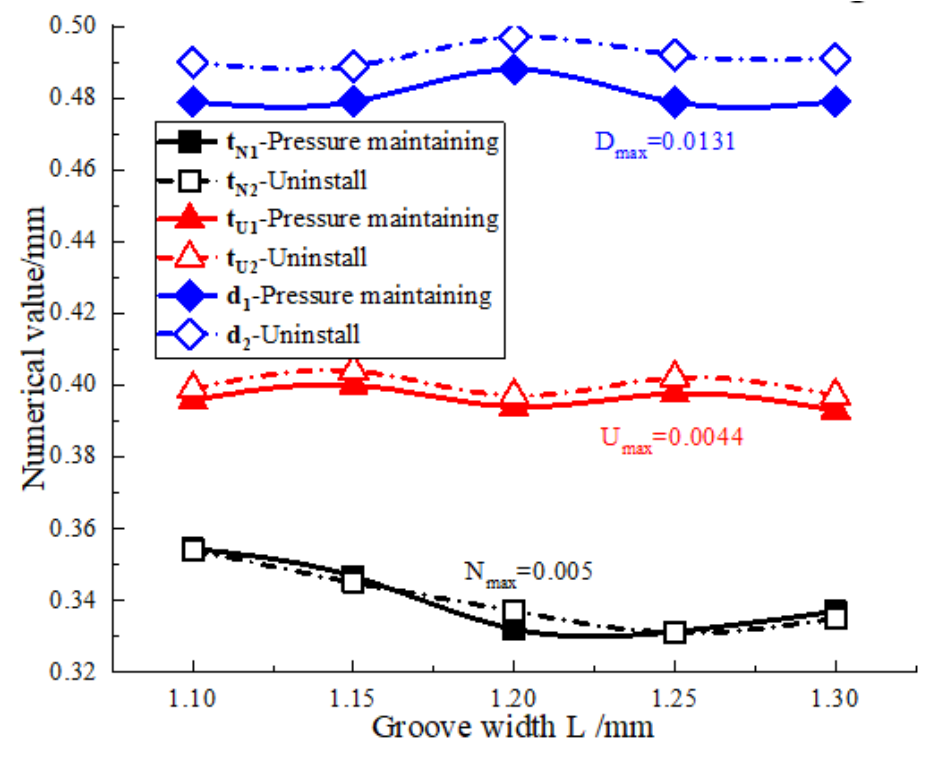

(a) critical dimensions

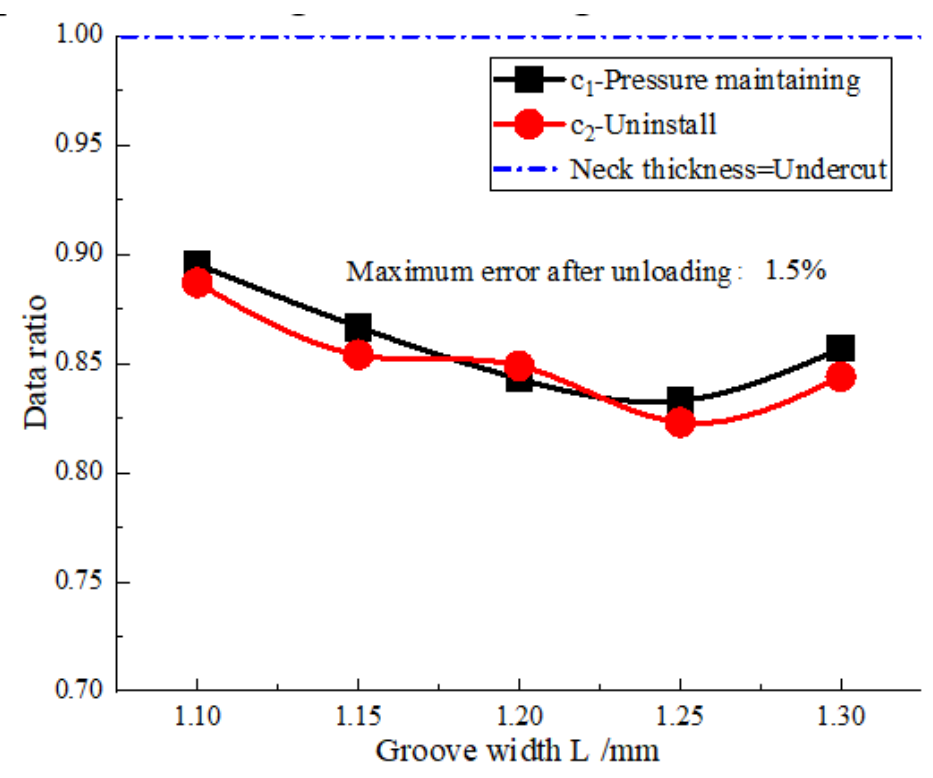

(b) neck-lock ratio

Figure 16

Effect of groove width on forming quality of joint
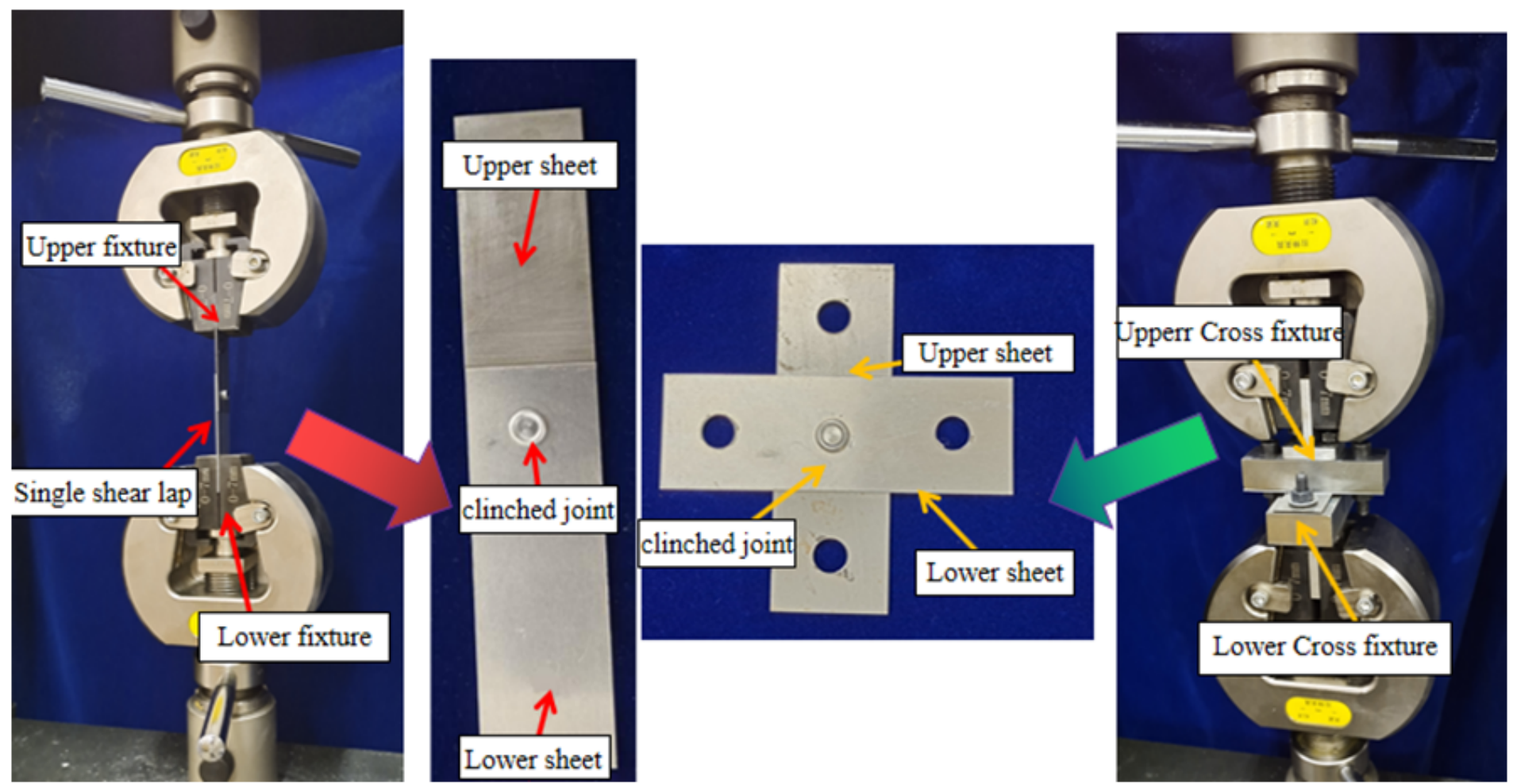
Upperr Cross fixture

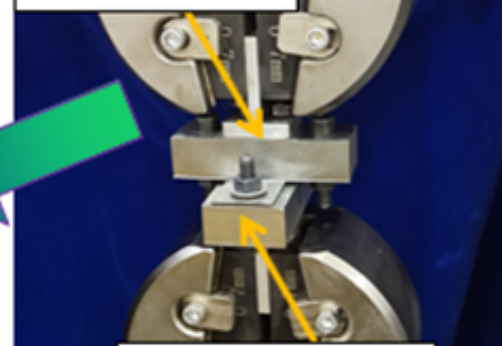

Lower Cross fixture

Figure 17

The equipment and sample of tensile and shear strength test 


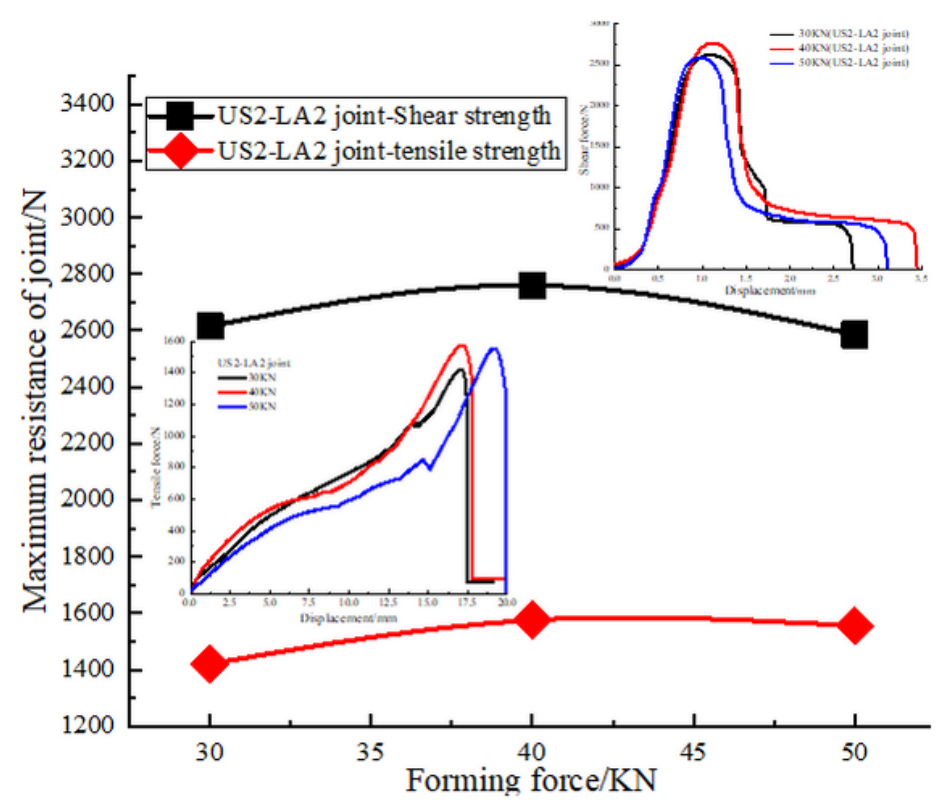

(a) Tensile and shear strength

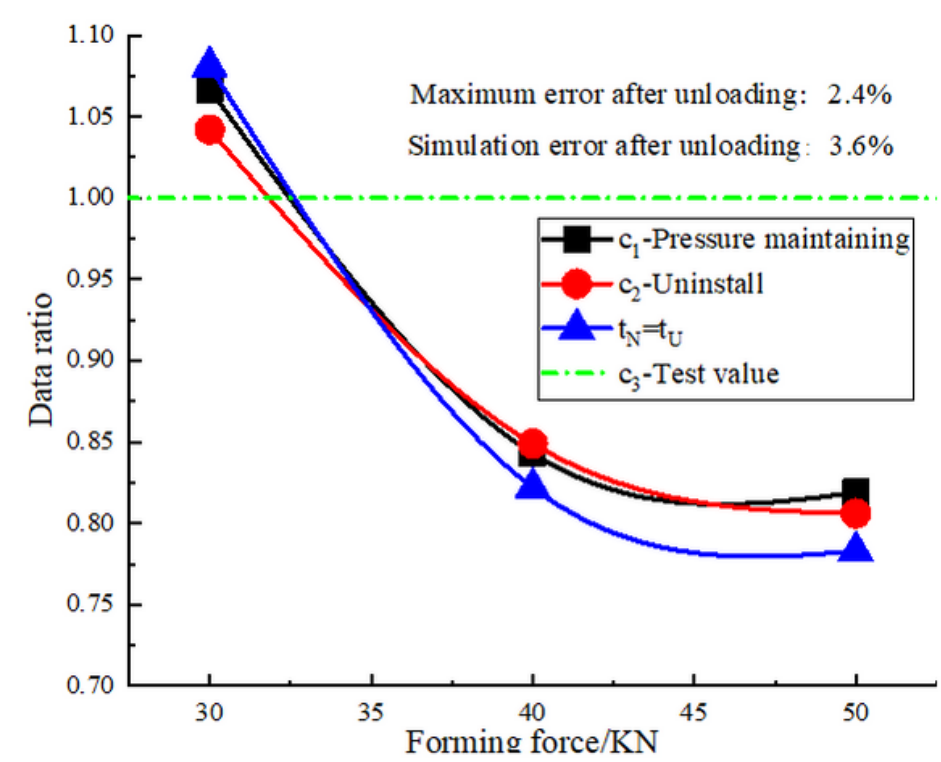

(b) neck-lock ratio

Figure 18

Comparison of joint strength and neck-lock ratio under different forming forces 


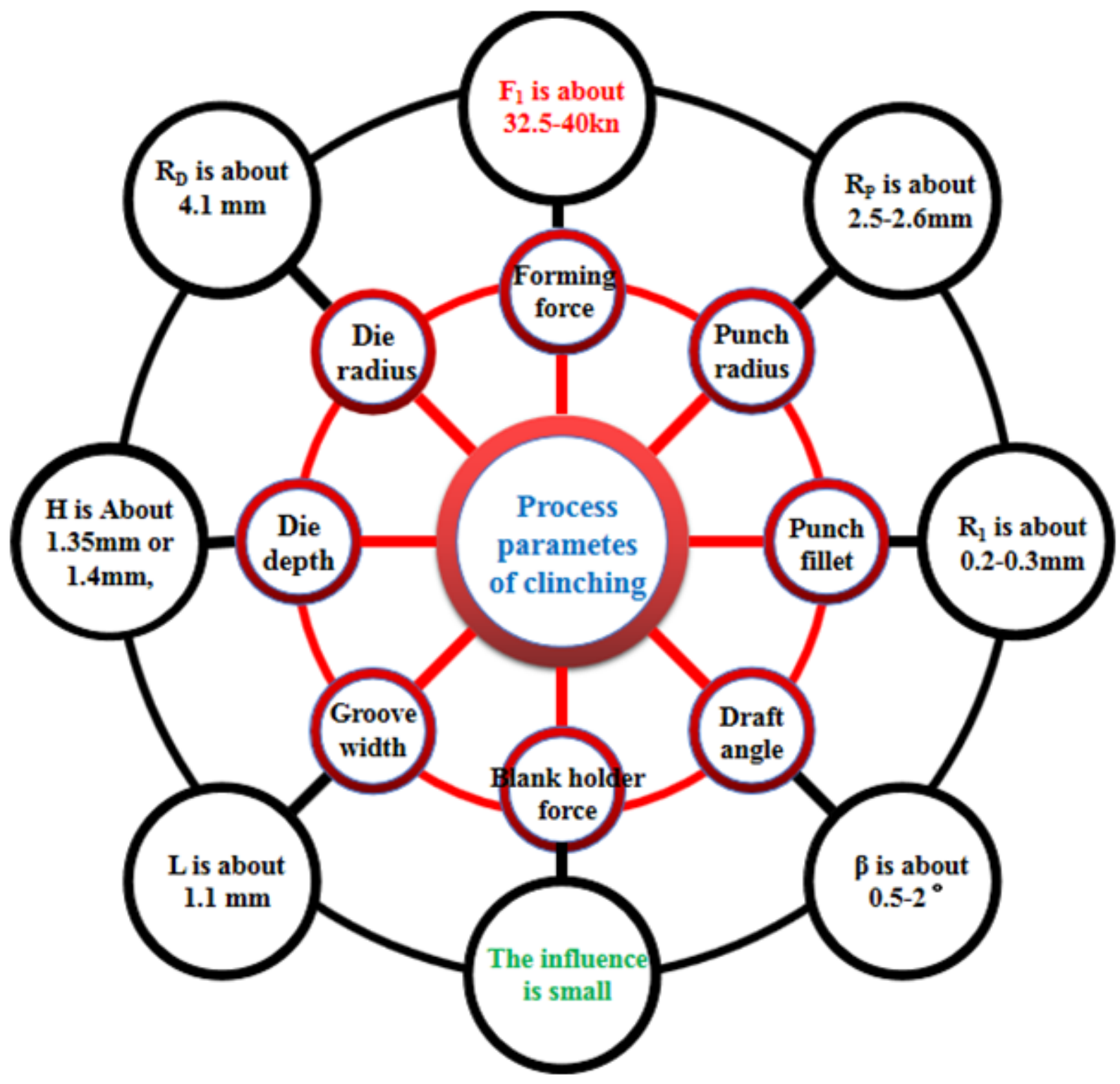

Figure 19

Schematic diagram of selection of different process parameters 